\title{
Low oxygen post conditioning improves stroke-induced cognitive impairment.
}

\section{Zidan Zhao, PhD}

School of Biomedical Sciences and Pharmacy and Priority Research Centre for Stroke and Brain Injury, University of Newcastle, NSW, Australia. Hunter Medical Research Institute, NSW, Australia.

\section{Lin Kooi Ong, PhD}

School of Biomedical Sciences and Pharmacy and Priority Research Centre for Stroke and Brain Injury, University of Newcastle, NSW, Australia. Hunter Medical Research Institute, NSW, Australia. NHMRC Centre of Research Excellence Stroke Rehabilitation and Brain Recovery, Australia.

Giovanni Pietrogrande, MSc

School of Biomedical Sciences and Pharmacy and Priority Research Centre for Stroke and Brain Injury, University of Newcastle, NSW, Australia. Hunter Medical Research Institute, NSW, Australia.

Sonia Sanchez Bezanilla, MSc

School of Biomedical Sciences and Pharmacy and Priority Research Centre for Stroke and Brain Injury, University of Newcastle, NSW, Australia. Hunter Medical Research Institute, NSW, Australia.

Kirby Warren, BBiomedSc (Hons)

School of Biomedical Sciences and Pharmacy and Priority Research Centre for Stroke and 
Brain Injury, University of Newcastle, NSW, Australia. Hunter Medical Research Institute, NSW, Australia.

Marina Ilicic, $\mathrm{PhD}$

School of Biomedical Sciences and Pharmacy and Priority Research Centre for Stroke and Brain Injury, University of Newcastle, NSW, Australia. Hunter Medical Research Institute, NSW, Australia.

Murielle G. Kluge, $\mathrm{PhD}$

School of Biomedical Sciences and Pharmacy and Priority Research Centre for Stroke and Brain Injury, University of Newcastle, NSW, Australia. Hunter Medical Research Institute, NSW, Australia.

\section{Clifford TeBay, BBiomedSc}

School of Biomedical Sciences and Pharmacy and Priority Research Centre for Stroke and Brain Injury, University of Newcastle, NSW, Australia. Hunter Medical Research Institute, NSW, Australia.

Ole P. Ottersen, MD, PhD

Division of Anatomy, Department of Molecular Medicine, Institute of Basic Medical Sciences, University of Oslo, Oslo, Norway. Office of the President, Karolinska Institutet, Stockholm, Sweden.

Sarah J Johnson, $\mathrm{PhD}$

School of Electrical Engineering and Computing, University of Newcastle, NSW, Australia. 
Michael Nilsson, MD, $\mathrm{PhD} \dagger$

Centre for Rehab Innovations, University of Newcastle, Callaghan, NSW, Australia. Priority Research Centre for Stroke and Brain Injury, University of Newcastle, NSW, Australia. Hunter Medical Research Institute, NSW, Australia. NHMRC Centre of Research Excellence Stroke Rehabilitation and Brain Recovery, Australia.

Frederick R Walker, $\mathrm{PhD} \dagger$

School of Biomedical Sciences and Pharmacy and Priority Research Centre for Stroke and Brain Injury, University of Newcastle, NSW, Australia. Hunter Medical Research Institute, NSW, Australia. NHMRC Centre of Research Excellence Stroke Rehabilitation and Brain Recovery, Australia.

Address for correspondence: University of Newcastle, Callaghan, NSW, Australia. Phone: +612 4921 5012; Email: rohan.walker@newcastle.edu.au

$\dagger$ Contributed equally to senior authorship. 


\begin{abstract}
Post-stroke cognitive impairment has proven to be notoriously difficult to treat. In the current study, we sought to both better understand cellular changes that underpin cognitive deficits and to consider the potential restorative benefits of low oxygen post conditioning (LOPC). We were motivated to use LOPC as an intervention as it is one of the few experimental interventions previously shown to improve cognitive function post-stroke. Experimental stroke was induced by photothrombotic occlusion in adult male C57BL/6 mice. Mice were randomly assigned to either a normal atmospheric air exposure or low oxygen $\left(11 \% \mathrm{O}_{2}\right)$ exposure groups three days post-occlusion. On day 17 post-stroke, mice were euthanized for histology or biochemical analyses. Stroked mice exposed to LOPC was associated with marked reductions in amyloid-beta both in its absolute level and in the extent of its oligomerization. Exposure to LOPC post-stroke also improved cellular deficits induced by stroke including an increase in vessel density, a reduction in vascular leakage, and restoration of AQP4 polarisation. Critically, stroked mice exposed to LOPC exhibited robust improvements in cognitive function post-stroke, assessed using a touchscreen based pairedassociate learning task. These findings provide compelling pre-clinical evidence of the potential clinical utility of LOPC for enhancing recovery post-stroke.
\end{abstract}

Keywords: Stroke recovery, cerebrovascular, glial cells, amyloid-beta, cognitive function 


\section{Introduction}

While cognitive impairment is recognised to represent a major challenge for stroke survivors, there are currently no accepted clinical interventions for improving cognition poststroke. $^{1,2}$ The paucity of effective pro-cognitive treatments has led to extensive pre-clinical efforts to develop innovative approaches to improve cognitive performance post-stroke. ${ }^{3,4}$

One of the most promising pro-cognitive approaches identified to date has been intermittent exposure to a reduced oxygen environment. ${ }^{5}$ In the context of stroke, exposure to low oxygen environment prior to induction of an ischemic event has been shown to produce robust neuroprotection. ${ }^{5}$ More recently, the benefits of low oxygen exposure have been considered when deployed after an ischemic event, low oxygen post conditioning (LOPC), arguably a more translationally relevant timeframe to consider. We have recently identified that LOPC produces significant improvement in motor function and neuroprotection after experimental stroke. ${ }^{6}$ Further, LOPC has been demonstrated to enhance levels of neurogenesis and long-term memory function. ${ }^{7-11}$

Currently, it is not clear why cognitive deficits appear post-stroke nor why exposure to a low oxygen environment appears capable remediating these impairments. With respect to inducing cognitive deficits, several mechanisms are likely to be contributing factors, including loss of neural tissue and vasculature, vascular leakage, compromised expression of vascular receptors involved in metabolic waste removal as well as enhanced accumulation of neurotoxic amyloid-beta $(A \beta)$ oligomers. ${ }^{12,13}$ Increased levels of soluble $A \beta$ accumulation, and in particular high molecular weight oligomers have been linked to cognitive decline. ${ }^{14}$

It has been shown that post-stroke exposure to LOPC promotes neuronal survival and vascular growth. ${ }^{6,15}$ However, it unclear whether exposure to LOPC also improves other aspects of vascular function, or whether these improvements can modulate $A \beta$ burden. As such, the current study sought to understand how stroke may impair key mechanisms that 
support cognition and how exposure to LOPC may influence these same mechanisms. To address these questions we exposed adult male mice to either regular atmospheric air poststroke or to LOPC (11\% oxygen, either $8 \mathrm{~h}$ or $24 \mathrm{~h} /$ day for 14 days). We assessed cognition using a rodent touchscreen platform for paired-associate learning (PAL) task, and investigated changes in cellular and molecular compositions of the peri-infarct territory. 


\section{Materials and Methods}

The data that support the findings of this study are available from the corresponding author upon reasonable request. A detailed materials and methods section is available in the Supplementary material.

\section{Ethical statements}

Animal research was undertaken in accordance with ARRIVE guidelines. Experiments were approved by the University of Newcastle Animal Care and Ethics Committee (A-2013-338), and conducted in accordance with the New South Wales Animals Research Act and the Australian Code of Practice for the use of animals for scientific purposes.

\section{Animals}

C57BL/6 male mice (eight weeks old) were obtained from the Animal Services Unit at the University of Newcastle. Mice were maintained in a temperature $\left(21^{\circ} \mathrm{C} \pm 1\right)$ and humiditycontrolled environment with food and water available ad libitum. Lighting was on a 12:12 $\mathrm{h}$ reverse light-dark cycle (lights on 19:00 h) with all procedures conducted in the dark phase. Mice were habituated for a minimum of seven days prior to the start of the experiment.

\section{Randomization and Blinding}

In all instances mice were randomly allocated to experimental groups. All outcome analyses were performed by independent study team members blinded to the treatment condition.

\section{Experimental design}

A total of $128 \mathrm{C} 57 \mathrm{BL} / 6$ adult male mice were each randomly allocated to one of the following four groups: sham, stroke, stroke with exposure to 8h/daily of LOPC (LOPC 8h), 
and stroke with 24h/daily of LOPC (LOPC $24 \mathrm{~h}$ ). Each cohort of 32 mice ( 8 per group) were used for either behavioural testing, fixed tissue analysis (immunohistochemistry), western blotting, or PCR analysis. Brains and blood samples were collected at day 17 post-stroke.

\section{Animal surgery and low oxygen post conditioning}

Photothrombotic vascular occlusion was performed as previously described. ${ }^{16,}{ }^{17}$ Briefly, mice were anaesthetized by $2 \%$ isoflurane during surgical procedure on a temperature controlled $\left(37^{\circ} \mathrm{C} \pm 1\right)$ stereotaxic frame. The skull was exposed by incision of the skin along the midline of the scalp. Rose Bengal $(200 \mu \mathrm{L}, 10 \mathrm{mg} / \mathrm{ml}$ solution in sterile saline, SigmaAldrich, USA) was injected intraperitoneally. After $8 \mathrm{~min}$, the skull was illuminated for 15 min by a $4.5 \mathrm{~mm}$ diameter cold light source positioned at $2.2 \mathrm{~mm}$ left lateral of Bregma, targeting the left motor and somatosensory cortices. For the sham group, the same surgical procedure was applied except Rose Bengal was replaced with $200 \mu \mathrm{L}$ of sterile saline $(0.9 \%$ $\mathrm{NaCl}$, Pfizer, Australia). Mice were subjected to the low oxygen environment starting at 3 days post-stroke. Low oxygen exposure was achieved using a customized ventilated cage racking system that was retrofitted to accept $11 \%$ oxygen, provided by a pressure swing adaptor based hypoxic generator. ${ }^{6}$ The levels for $\mathrm{CO}_{2}$ were monitored and remained at atmospheric levels $\sim 350 \mathrm{ppm}$ and normal sea level atmospheric pressure $(101 \mathrm{kPa})$ within the conditioned chambers. Mice from the two exposure low oxygen conditions, LOPC $8 \mathrm{~h}$ and LOPC $24 \mathrm{~h}$, were maintained in a low oxygen environment for either $8 \mathrm{~h}$ (10am to $6 \mathrm{pm})$ or $24 \mathrm{~h}$, respectively for two weeks. Sham and stroke only mice were handled for 2 min twice daily throughout the duration of experiment.

\section{Assessment of cognitive deficits}

Associative memory cognitive domain was assessed in mice using the touchscreen platform 
for PAL task. ${ }^{18,19}$ Touchscreen operant chambers (Campden Instruments Ltd., UK, Figure 1(a)) were used in the testing, and by their nature are inherently blinded. ${ }^{18,20}$ A liquid reward (strawberry milkshake; Paul's Milky Max) was provided to motivate animals' performance. The task consists of two distinct phases: basic training, whereby the animal learns the association between making contact with the screen and the actual PAL task. Habituation/basic training was done before stroke and PAL task learning was commenced three days post-stroke. Eight animals per group (total 32 animals) were used in the PAL testing.

Habituation/basic training: Before stroke, all mice were trained to touch the screen in order to receive the liquid reward. In order to receive a reward, animals were required to make contact with the screen when it was illuminated. Over 9 days all animals learnt to respond to screen illumination, with a minimum of $80 \%$ correct rate of response. Following general touchscreen training, mice underwent photothrombotic occlusion surgery.

PAL task learning: Three days post-surgery mice in the sham and stroke groups $( \pm \mathrm{LOPC})$ commenced the PAL task. In the task, three stimuli images (a flower, plane and spider) were associated with a specific spatial location (left, center, right, respectively). In each trial, two images were displayed at the same time, one in the correct location and the other in an incorrect location (Figure. 1(a)). All trials were mouse initiated and independent of the experimenter. If the animal touched the image in its correct location, a reward was provided (a correct trial was recorded). After reward collection, the next trial was initiated. If the animal touched the incorrect image or the correct image in its incorrect location, it was punished by the absence of strawberry milkshake, no tone, and $5 \mathrm{~s}$ house light on (incorrect trial). After 20s inter-trial interval, a repeat trial with presentation of the same stimuli was 
initiated (a repeated trial). This process was repeated until the mouse made the correct choice or $1 \mathrm{~h}$ had elapsed. The number of repeated trials (also termed the perseveration index) was recorded and was not counted in the total trials administered or the correct rate (i.e $\%$ of correct trials). The time to finish each task was also recorded. The testing was terminated if the mouse successfully completed 36 trials or the testing session was 1 hour in length (which ever happened first).

\section{Haematocrit assessment}

Blood haematocrit levels were measured using the i-STAT system and CG8 cartridges (Abbott Point of Care).

\section{Tissue processing}

At day 17 post-stroke, mice were euthanized. For immunohistochemical analysis, animals (n $=8$ per group) were deeply anesthetized via intraperitoneal injection of sodium pentobarbital and transcardially perfused with ice cold $0.9 \%$ saline for 2 mins followed by ice cold $4 \%$ paraformaldehyde ( $\mathrm{pH}$ 7.4) for 13 mins. Brains were removed and post-fixed for 4 hours in the same fixative then transferred to a $12.5 \%$ sucrose solution in $0.1 \mathrm{M}$ PBS for storage and cyroprotection. Serial coronal sections were sliced on a freezing microtome $\left(-25^{\circ} \mathrm{C}\right)$ at a thickness of $30 \mu \mathrm{m}$. For western blot and PCR analysis, animals $(n=8$ per group for western blot and PCR analysis, respectively) were deeply anesthetized via intraperitoneal injection of sodium pentobarbital and transcardially perfused with ice cold $0.1 \%$ diethylpyrocarbonate in $0.9 \%$ saline for 2 mins. Brains were dissected and rapidly frozen in $-80^{\circ} \mathrm{C}$ isopentane. Sections were sliced using a cryostat $\left(-20^{\circ} \mathrm{C}\right)$ at a thickness of $200 \mu \mathrm{m}$ and the peri-infarct territory ( $2 \mathrm{~mm} 2$ around infarct core) were punched using a $1 \mathrm{~mm}$ tissue punch. Samples were kept frozen at all times until protein and mRNA extraction. 


\section{Histology and immunohistochemistry analysis}

For immunoperoxidase labelling, free floating sections were immunostained as previously described $^{17,21}$, with one of the following primary antibodies: mouse anti-NeuN, mouse antiGFAP, rabbit anti-Iba-1, rabbit AQP4, biotinylated goat anti-IgG. All antibodies details have been provided in Table I. Sections to be immunolabelled with rabbit anti-collagen IV additionally underwent pepsin antigen retrieval using the method described by S. Franciosi et $\mathrm{al}^{22}$ Sections were rinsed with $0.1 \mathrm{M}$ PB and endogenous peroxidases were quenched in 0.1 M PB containing 3\% hydrogen peroxide. Non-specific binding was blocked with 3\% normal horse serum. Sections were incubated in primary antibody with $2 \%$ normal horse serum for 48 hours at $4 \mathrm{C}^{\circ}$ and then were washed in $0.1 \mathrm{M}$ PBS for $30 \mathrm{~min}$ and incubated with a biotinylated secondary antibody of corresponding species for $2 \mathrm{~h}$ at room temperature, rinsed, incubated in $0.1 \%$ extravadin peroxidase for $1 \mathrm{~h}$, and then rinsed again. Immunolabelling was developed using a nickel-enhanced 3, 3'-diaminobenzidine (DAB) reaction. Tissues from the four experimental groups were performed simultaneously and the DAB reactions were developed for exactly the same length of time following the addition of glucose oxidase (1:1000). Negative control sections, in which no primary antibodies were added, were developed at the same time to confirm the specificity of labelling. After processing was completed sections were washed, mounted onto chrome alum-coated slides and coverslipped.

\section{Image acquisition, tissue loss, cell count, thresholding and AQP4 polarization analysis}

Images were acquired at $20 \mathrm{X}$ using Aperio AT2 (Leica, Germany). ImageJ (1.50, NIH) and Matlab (R2015a, MathWorks) were used to quantitate tissue loss, cell count, Aquaporin-4 (APQ4) vessel/parenchymal ratio, and to analyse intensity and area coverage of 
immunolabelling. ${ }^{16,17,19,23-25}$ To estimate tissue loss within the infarcted hemisphere, the area of contralateral and ipsilateral hemispheres were measured across four sections (at Bregma level +1.0, 0.0, -1.0 and $-2.0 \mathrm{~mm}$, Figure 2(a)) using Image J. The $\%$ tissue loss was determined by the equation: [(average area of contralateral hemisphere - average area of ipsilateral hemisphere)/ area of contralateral hemisphere] x $100 \%$. The quantitative analysis was undertaken specifically in the peri-infarct territory as defined by $0.01 \mathrm{~mm}$ from infarct, the region was $0.25 \mathrm{~mm}$ by $0.5 \mathrm{~mm}$ in size. Cumulative threshold analysis was performed using Matlab functions. Firstly, for each of the acquired images, the number of pixels occurring at each of the pixel intensities was determined. The pixel intensity values are then rank ordered 0-255 along with the corresponding number of pixel that occur at each value. For the purposes of analysis, we calculated the percentage of cumulative threshold material for the range of pixel intensity values (Figure 7). Pixel intensity level considered to be optimal for detecting genuine differences in immunoreactive signal was determined using ImageJ software to visualize thresholding of cropped regions at individual pixel intensities. This threshold level was used to investigate group differences for all labels. For NeuN, GFAP and Iba-1 positive cell counts, exhaustive manual cell counts were undertaken within the cropped regions (Bregma 0.0mm, Figure 2(a)). The vessel digital reconstruction was performed as previously described. ${ }^{19,26,27}$ Collagen IV positive cells were isolated from the background using multi-level Otsu's thresholding method, which calculates the threshold that minimizes the interclass pixel intensity variance between groups. Using Matlab functions we determined percentage area covered by the labelling. AQP4 analysis involved quantifying the intensity of AQP4 labelling on the vessel lumen relative to that in the adjacent parenchyma (APQ4 vessel/parenchymal ratio).

\section{Biochemical analysis}


Protein homogenates from peri-infarct samples were obtained and Western blotting was performed as previously described. ${ }^{16,17}$ PVDF membranes were incubated with primary antibody anti-amyloid $\beta$ (D3D2N) overnight at $4^{\circ} \mathrm{C}$, followed by secondary antibody antiMouse-HRP antibody for $1 \mathrm{~h}$ at $25^{\circ} \mathrm{C}$. In between each incubation step, membranes were washed in TBS-T. Membranes were visualized on Amersham Imager 600 using Luminata Forte Western blotting detection reagents. The density of the bands was measured using Amersham Imager 600 Analysis Software. RNA was isolated from the peri-infarct samples using the Illustra RNAspin Kit (GE Healthcare, Cat\#25-0500-70) according to manufacturer's specifications. Quantitative RT-PCR was performed as previously described. ${ }^{28}$ cDNA was generated using SuperScript ${ }^{\mathrm{TM}}$ III First Strand Synthesis System for RT-PCR (Invitrogen, Cat\# 18080-044) according to manufacturer's instructions on a GeneAmp PCR System 9700 instrument (Applied Biosystems). Quantitative RT-PCR was performed on an Applied Biosystems ${ }^{\circledR} 7500$ (Applied Biosystems) or ViiA7 (Thermofisher) instruments using SensiFAST SYBR® Lo-ROX Master Mix (Bioline, Cat\# BIO-94020). Genes of interest (Table II) were normalized on the housekeeping gene GAPDH and data are expressed as $2-\Delta \Delta \mathrm{Ct}$ as fold change relative to sham.

\section{Statistical analysis}

All data for sham, stroke, LOPC $8 \mathrm{~h}$ and LOPC $24 \mathrm{~h}$ groups were expressed as mean \pm SD and were analysed using Prism 6 for Windows Version 6.01, GraphPad Software. Two-way ANOVA was used to determine whether there were time and treatment effects across groups in the PAL task. All other experiments used One-Way ANOVA to determine whether there were any significant treatment effects across the groups. Additional Tukey multiple comparisons were used to analyse differences between the mean of each group and the mean of every other group. The significant differences shown on the graphs with asterisks (*) refer 
bioRxiv preprint doi: https://doi.org/10.1101/483453; this version posted November 30, 2018. The copyright holder for this preprint (which was not certified by peer review) is the author/funder. All rights reserved. No reuse allowed without permission.

to the post hoc tests. All differences were considered to be significant at $p<0.05$. 


\section{Results}

\section{Low oxygen post conditioning increases haematocrit in mice}

To confirm the biological effect of the LOPC protocol, haematocrit assessment was performed 14 days following LOPC treatment (17 days post-stroke). We identified that there was no significant difference between sham and stroke animals $(0.38 \pm 0.006$ vs. $0.38 \pm 0.005$, $p=0.97)$. The stroked LOPC $8 \mathrm{~h}(0.48 \pm 0.005)$ and LOPC $24 \mathrm{~h}(0.49 \pm 0.008)$ animals had a significantly higher haematocrit than stroke only animals $(p<0.001$ and $p<0.001$, respectively).

\section{Low oxygen post conditioning ameliorates cognitive deficit after stroke}

In order to assess whether LOPC treatment improved cognitive outcomes post-stroke, animals were exposed to LOPC for $8 \mathrm{~h}$ or $24 \mathrm{~h}$ alongside daily PAL touchscreen task for 2 weeks (Figure 1(a)).

Analysis of the \% correct responses indicated that there was a main effect for each of treatment group $(\mathrm{F}=118.3, \mathrm{p}<0.001)$ and time $(\mathrm{F}=4.16, p<0.05)$ (Figure 1(b)). In the second week of testing we identified that the animals exposed to stroke performed significantly lower than the sham $(p<0.05)$, LOPC $8 \mathrm{~h}(p<0.05)$ and LOPC $24 \mathrm{~h}(p<0.01)$ groups.

Analysis of the number of repeated trials per task revealed a significant main effect for group $(\mathrm{F}=77.90, p<0.001)$ and time $(\mathrm{F}=6.36, p<0.01)$ (Figure 1(c)). In the first week, stroked animals performed significantly more repeated trials when compared to the sham $(p<0.01)$, LOPC $8 \mathrm{~h}(p<0.05)$ and LOPC $24 \mathrm{~h}(p<0.05)$ groups. In the second week of training stroked animals still performed a greater number of repeated trials when compared to sham $(p<0.05)$, however there was no significant difference between stroke and LOPC $8 \mathrm{~h}(p=0.08)$ or LOPC $24 \mathrm{~h}$ animals $(p=0.07)$.

Analysis of seconds per task revealed a significant main effect for group $(\mathrm{F}=5.60, p<0.01)$ 
and time $(\mathrm{F}=84.59, p<0.001)$ (Figure $1(\mathrm{~d})$ ). In the first week, stroked animals took significantly longer time per task when compared to the sham $(p<0.01)$, LOPC $8 \mathrm{~h}(p<0.05)$ and LOPC $24 \mathrm{~h}(p<0.05)$ groups. In the second week of training stroked animals still took significantly longer time per task when compared to sham $(p<0.05)$ and LOPC $24 \mathrm{~h}(p<0.05)$ animals, however there was no significant difference between stroke and LOPC $8 \mathrm{~h}$ animals $(p=0.11)$.

Analysis of latency of reward collection revealed a significant main effect for group $(\mathrm{F}=5.27$, $p<0.01)$ and time $(\mathrm{F}=14.03, p<0.001)$ (Figure 1(e)). In the first week, stroked animals took significantly longer time to collect reward when compared to the sham $(p<0.01)$, LOPC $8 \mathrm{~h}$ $(p<0.01)$ and LOPC $24 \mathrm{~h}(p<0.01)$ groups. There was no statistically significant deference between groups in the second week.

[insert Figure 1.]

\section{Low oxygen post conditioning reduces tissue loss and neuron loss after stroke}

Total brain tissue volume and neuronal cell population were examined using immunohistochemistry (Figure 2). There was a statistically significant increase in average volume of tissue loss in stroke animals compared to sham animals $(p<0.001)$. The average volume of tissue loss in the LOPC $8 \mathrm{~h}$ and LOPC $24 \mathrm{~h}$ animals was significantly smaller than observed in stroke only animals $(\mathrm{F}=16.68, p<0.001$ and $p<0.001$, respectively, Figure 2(c)). Mature neuronal marker NeuN was used to assess the neuronal cell loss in the peri-infarct regions after stroke. Exhaustive manual cell counts were undertaken within the cropped regions indicated in Figure 2(a). Stroke animals significantly reduced numbers of NeuN positive cells in the peri-infarct territory compared to sham animals $(\mathrm{F}=18.44, p<0.001)$, a state that was restored in both LOPC $8 \mathrm{~h}$ and LOPC 24h animals $(p<0.05$ and $p<0.05$, 
respectively. Figure 2(d)).

[insert Figure 2.]

\section{Low oxygen post conditioning promotes cerebrovascular remodelling and microglia}

\section{activation}

Cerebrovascular remodelling was examined by threshold analysis and digital vessel reconstruction of Collagen IV labelling in order to determine whether LOPC stimulated angiogenesis (Figure 3(a)). For thresholding analysis, the data for each group was expressed as a fold increase of the mean $\pm \mathrm{SD}$ relative to the mean of the sham group (for cumulative threshold analysis see the Supplementary material). Stroke animals had significantly reduced Collagen IV immunoreactivity levels and percentage area covered by Collagen IV positive cells in the peri-infarct territory, compared to sham animals $(\mathrm{F}=28.47, p<0.05$ and $\mathrm{F}=10.02$, $p<0.05$, respectively). Both LOPC $8 \mathrm{~h}$ and LOPC $24 \mathrm{~h}$ significantly promoted the density and distribution of Collagen IV compared to the stroke only animals.

To investigate whether LOPC influenced glial cells in the peri-infarct territory following stroke, we performed threshold analysis and cell counts using astrocyte marker, GFAP, and microglia marker, Iba-1 (Figure 3(d) and (g)). Stroke induced a significant increase in both GFAP and Iba-1 immunoreactivity relative to sham animals $(\mathrm{F}=55.06, p<0.001$ and $\mathrm{F}=31.72$, $p<0.001$, respectively). This corresponded with an increase in the number of GFAP and Iba-1 positive cells in stroke animals compared to sham animals $(\mathrm{F}=108.5, p<0.001$ and $\mathrm{F}=72.68$, $p<0.001$, respectively). LOPC $8 \mathrm{~h}$ exhibited modestly elevated thresholded immunoreactivity levels of GFAP to stroked animals. LOPC $8 \mathrm{~h}$ and LOPC $24 \mathrm{~h}$ significantly increased thresholded immunoreactivity levels and Iba-1 positive cells to stroke animals. 
[insert Figure 3.]

\section{Low oxygen post conditioning reduces Aß oligomer accumulation after stroke}

The tissue samples from the peri-infarct territory were analysed by western blot using anti-A $\beta$ for soluble $\mathrm{A} \beta$ oligomers. The results for $\mathrm{A} \beta$ oligomers at $56 \mathrm{kDa}$ (dodecamer), $50 \mathrm{kDa}$ (decamer), 25kDa (pentamer), 5kDa (monomer) and total $\mathrm{A} \beta$ (5-200kDa) levels were normalized to $\beta$-actin as loading control (Figure 4). Data for all groups were expressed as a fold increase of the mean $\pm \mathrm{SD}$ for each group relative to the mean of the sham group. All $\mathrm{A} \beta$ oligomers showed similar patterns. Specifically, at $56 \mathrm{kDa}, 50 \mathrm{kDa}, 25 \mathrm{kDa}$, and total $\mathrm{A} \beta$ levels, were elevated in the stroke group relative to sham animals $(\mathrm{F}=10.44, p<0.001$; $\mathrm{F}=28.60, p<0.001 ; \mathrm{F}=12.10, p<0.001$ and $\mathrm{F}=12.14, p<0.001$, respectively). Both the LOPC $8 \mathrm{~h}$ and LOPC $24 \mathrm{~h}$ displayed lower levels of oligomerization relative to the stroke alone condition (LOPC 8h; $p<0.05, p<0.001, p<0.05, p<0.05$ and LOPC 24h; $p<0.01, p<0.001$, $p<0.05, p<0.001$, respectively). At $5 \mathrm{kDa}$ level, stroke induced a significant increase relative to sham animals $(\mathrm{F}=3.01, p<0.05)$, but there was no significant difference compared to LOPC $8 \mathrm{~h}$ and LOPC $24 \mathrm{~h}(p=0.23$ and $p=0.15$, respectively).

[insert Figure 4.]

\section{LOPC alters APP and BACE mRNA expression}

We investigated changes in the expression levels of several key genes involved in the generation, degradation and export of A $\beta$ using qPCR (Figure 5), specifically amyloid precursor protein (APP); beta-secretase (BACE); TNF $\alpha$ converting enzyme (TACE); neprilysin, (NEP); endothelin-converting enzyme (ECE); insulin-degrading enzyme (IDE); 
low-density lipoprotein receptor-related protein-1 (LRP1); and receptor for advanced glycation end products (RAGE). Stroke animals exhibited a significant decrease in the expression of APP and BACE mRNA levels relative to sham animals $(\mathrm{F}=16.56, p<0.001$ and $\mathrm{F}=4.61, p<0.05$, respectively). This reduction of APP and BACE mRNA levels was reversed by both LOPC $8 \mathrm{~h}$ and LOPC $24 \mathrm{~h}$. Stroke alone induced a significant increase in the expression of TACE and NEP mRNA levels relative to sham animals $(\mathrm{F}=11.13, p<0.001$ and $\mathrm{F}=20.62, p<0.001)$. However, stroke alone induced a significant decrease in the expression of ECE mRNA levels relative to sham animals $(\mathrm{F}=17.14, p<0.001)$. LOPC $8 \mathrm{~h}$ modestly elevated LRP1 and RAGE mRNA levels ( $p<0.001$ and $p<0.05$, respectively), and LOPC $24 \mathrm{~h}$ increased ECE mRNA levels $((p<0.001)$, relative to stroke only animals.

[insert Figure 5.]

\section{LOPC improves vascular leakage and AQP4 polarization after stroke}

Stroke-induced cerebrovascular leakage was assessed by $\operatorname{IgG}$ staining in the peri-infarct regions (Figure 6(a)). A significant increase in $\operatorname{IgG}(\mathrm{F}=13.87, p<0.001)$ was present in stroke animals compared to sham animals. Vascular leakage was improved significantly by exposure to LOPC $24 \mathrm{~h}(p<0.001)$, however there was no significant difference between LOPC $8 \mathrm{~h}$ and stroke only animals $(p=0.45)$.

AQP4 polarization was calculated as the ratio of AQP4 labelling on the vessel wall to that in the parenchymal tissue directly adjacent to the vessel (Figure 6(b)). AQP4 polarization towards vessel wall was reduced significantly in peri-infarct regions of stroke compared to sham animals $(\mathrm{F}=29.46, p<0.001)$. This reduction was improved by both LOPC $8 \mathrm{~h}$ and LOPC $24 \mathrm{~h}(p<0.05$ and $p<0.05$ respectively). 
bioRxiv preprint doi: https://doi.org/10.1101/483453; this version posted November 30, 2018. The copyright holder for this preprint (which was not certified by peer review) is the author/funder. All rights reserved. No reuse allowed without permission.

[insert Figure 6.] 


\section{Discussion}

This is the first study, to our knowledge, to demonstrate that exposure to low oxygen post conditioning (LOPC) is capable of reducing the accumulation and aggregation of soluble A $\beta$ oligomers post-stroke. We have shown that a focal cortical photothrombotic stroke is responsible for inducing significant impairment of cognitive function as evaluated by the performance of the PAL task. We have demonstrated that exposure to LOPC for either $8 \mathrm{~h}$ or 24h a day for two weeks post-occlusion was sufficient to improve the associative memory deficits induced by stroke. The improvement in cognition observed in animals exposed to LOPC was associated with marked reductions in total level of the neurotoxic protein, $A \beta$, both in its absolute level and in the extent of its oligomerization. LOPC was also associated with several improvements in vessel density, a reduction in vascular leakage, and restoration of AQP4 polarisation. Collectively, these findings point to the potential utility of LOPC as a therapeutic tool to improve cognition post-stroke.

In the current study, we chose to assess changes in cognition using the PAL task. The PAL test is a well-described cognitive assessment task, and was chosen as PAL deficits have been identified in patients post-stroke and in the earliest stages of Alzheimer's disease. ${ }^{29-31}$ The rodent version of the PAL task used in the current study has been validated as a sensitive tool for identifying complex cognitive deficits in rodents. ${ }^{18}$ We identified that animals exposed to stroke exhibited robust deficits in two key metrics, namely the \% of correct trials performed, which is considered to reference both learning and memory, as well as the number of repeated trials, which is considered to index perseveration. ${ }^{18,32,33}$ Both the LOPC paradigms limited these deficits to a level that was comparable to that observed in sham animals. These findings align well with other studies that illustrate the effectiveness of LOPC to improve cognitive deficits after stroke. ${ }^{10,11}$

A significant focus of the work undertaken in this study was to understand the 
mechanisms through which exposure to LOPC improves cognition. The most obvious explanation for the pro-cognitive effects of LOPC was that the intervention is neuroprotective. ${ }^{15}$ Consistent with this general postulation, we observed a neuroprotective effect of LOPC using two indices. Firstly, we identified that mice exposed to LOPC for either $8 \mathrm{~h}$ or $24 \mathrm{~h}$ exhibited a reduced area of brain tissue loss relative to the stroke group, and secondly we demonstrated an increase in the number of NeuN+ neurons. It should be noted that glial cells, including astrocytes and microglia, have significant greater oxidative tolerance when compared to neurons. It will be of considerable interest to examine whether low oxygen exposure reduces cell death and removal or delayed injury in future studies.

An explanation for the neuronal protection conferred by LOPC was improvements within the neurovascular unit. The ability of low oxygen to stimulate growth of cerebrovasculature is well documented. ${ }^{5,6,34}$ We chose to investigate changes in vessel density using the vascular marker collagen IV, which labels the endothelial basement membrane. ${ }^{22}$ We identified that stroke resulted in a considerable reduction in vessel density within the peri-infarct territory, an effect that was largely attenuated via LOPC. It would be worthwhile in future studies to examine whether the new vessels are functional. Interestingly, we also identified that in addition to stimulating vessel growth, LOPC also resulted in a significant reduction in vascular leakage, as indexed by peri-vascular IgG labelling. This latter finding indicates that LOPC, in addition to stimulating vessel growth, produces a more mature vessel phenotype. Consistent with this we further observed that LOPC resulted in a restoration of AQP4 polarisation, a water channel, critical in facilitating the transit of cerebrovascular spinal fluid into the parenchyma. We also noted that LOPC resulted a mild stimulation of microglia, as evidenced by an enhanced level of Iba-1 expression. This modest enhancement is particularly interesting given the recent work demonstrating the essential role of microglia in mediating vascular repair. ${ }^{35-37}$ Further, characterising microglial engagement 
with vascular repair in the context of LOPC represents an area of future exploration.

We anticipated that if LOPC stimulated the development of the cerebrovasculature it may also promote the removal of neurotoxic proteins, such as $A \beta$, which is deposited at higher levels after stroke, and well recognised to disrupt neuronal function. ${ }^{13,16,38,39}$ As expected we identified that stroked animals exhibit greater levels of the soluble oligomers of A $\beta$. In comparison, stroked animals exposed to LOPC exhibited significant reductions in total levels of $\mathrm{A} \beta$, as well as exhibiting specific reductions in 25,50 and $56 \mathrm{kDa}$ oligomers relative to the stroke alone condition. To our knowledge, this is the first report to demonstrate that LOPC is capable of inducing robust decreases in total levels of amyloid and reducing aggregation of soluble $\mathrm{A} \beta$ oligomers post-stroke. It is important to recognise, however, that the relationship between the LOPC driven reduction in $\mathrm{A} \beta$ is associatively linked to the improvement in cognition. Future studies will be required to establish the causality of this relationship.

There are several possible explanations for the ability of LOPC to reduce the A $\beta$ burden post-stroke. For instance, changes in $A \beta$ may result from: changes in the rate of production of the amyloid precursor protein (APP); the rate of APP conversion into A $\beta$ (alpha- and beta-secretase); the extent of intracellular ingestion of $\mathrm{A} \beta$ and the actions of degrading enzymes (NEP, ECE and IDE). Alternatively, it may be influenced by the availability of vascular bound transporters (LRP-1) and the receptor for advanced glycation end (RAGE) products involved in the excretion of $A \beta$ or glymphatic clearance. ${ }^{40-42}$ While we did not quantify rates of glymphatic clearance we did identify that ability of LOPC to restore vascular polarisation of the AQP4 protein, a state which is considered to be essential for facilitating glymphatic flow. ${ }^{43,}{ }^{44}$ We additionally observed that stroke induced disturbances in expression levels of the APP and BACE mRNA expression and that LOPC returned these to the levels observed in sham animals. We could not, however, find any evidence to suggest 
that LOPC altered the expression of other enzymes involved in $A \beta$ formation or digestion including: TACE, NEP nor IDE. Modest elevations were observed in LOPC $8 \mathrm{~h}$ exposed animals over stroke alone in mRNA expression of the transport protein LRP-1 and the RAGE products. Together these results suggest that the improvement in $A \beta$ loading induced via LOPC is driven by a constellation of changes in the processing and removal of $A \beta$. However, the evidence suggests that the reduced levels of $A \beta$ are likely the result of improved vascular density and improved vascular transportation. ${ }^{45}$ Further experimentation here is required, ideally using the intracranial delivery of tagged-A $\beta$ that can be tracked in real-time. ${ }^{41}$

The ability of low oxygen exposure has long been recognised to be potently neuroprotective. ${ }^{5}$ Indeed, the therapeutic effects do not appear to be confined to the CNS, with Nakada et al. recently demonstrating the effectiveness of low oxygen exposure to improve heart regeneration following cardio myocyte loss. ${ }^{46}$ One of the principle advantages associated with reduced oxygen exposure interventions is that the approach triggers systemwide compensatory adaptions. The findings from this study further support the potential of LOPC for promoting recovery post-stroke. We have identified that exposure to a low oxygen environment for two weeks following stroke, beginning 3 days post-infarction, is sufficient enough to reduce neuronal loss, improve cognition, restore several of the vascular deficits as well se reduce the severity of the $A \beta$ burden. Stroke is known to trigger cognitive impairment and under certain circumstance trigger the emergence of dementia-like symptoms. A therapeutic strategy to reduce $A \beta$ and improve cognitive performance is highly desirable. ${ }^{39}$ As several human specific technologies already exist for controlled oxygen exposure, it is not inconceivable that future safety trials for this promising pro-cognitive intervention could be undertaken rapidly. 


\section{Acknowledgments}

We express our gratitude to HMRI Core Histology Facility for assistance with the immunohistochemistry images. We would like to acknowledge the insights and comments provided by Prof Jorgen Isgaard, Prof Neil Spratt and Dr Kirsten Coupland on early versions of the manuscript.

\section{Funding}

This study was supported by the NHMRC project grant (APP1142862), Hunter Medical Research Institute, The Brawn Bequest, Priority Research Centre for Stroke and Brain Injury Research Support Grant, Faculty of Health and Medicine Pilot Grant and University of Newcastle, Australia.

\section{Declaration of conflicting interests}

The author(s) declared no potential conflicts of interest with respect to the research, authorship, and/or publication of this article.

\section{Authors' contributions}

ZZ, MN and FRW designed the experiment. ZZ performed the majority of the experiments. LKO undertook all western blotting analyses and prepared the results for these data. GP undertook all mRNA analyses and prepared the results for these data. SSB, KW, MI, MK and CT assisted in the experiments. SJJ designed and prepared program for the image processing. ZZ, LKO, GP, OPO, SJJ, MN and FRW analyzed the data and interpreted the results. ZZ and FRW wrote the paper and LKO, GP, SSB, KW, MI, MK, CT, OPO, SJJ and MN revised all drafts and the manuscript. 


\section{References}

1. Levine DA, Galecki AT, Langa KM, et al. Trajectory of Cognitive Decline After Incident Stroke. JAMA 2015; 314: 41-51. DOI: 10.1001/jama.2015.6968.

2. Sun JH, Tan L and Yu JT. Post-stroke cognitive impairment: epidemiology, mechanisms and management. Ann Transl Med 2014; 2: 80. DOI: 10.3978/j.issn.23055839.2014.08.05.

3. Chung CS, Pollock A, Campbell T, et al. Cognitive rehabilitation for executive dysfunction in adults with stroke or other adult non-progressive acquired brain damage. Cochrane Database Syst Rev 2013: CD008391. DOI: 10.1002/14651858.CD008391.pub2. 4. Loetscher T and Lincoln NB. Cognitive rehabilitation for attention deficits following stroke. Cochrane Database Syst Rev 2013: CD002842. DOI: 10.1002/14651858.CD002842.pub2.

5. Baillieul S, Chacaroun S, Doutreleau S, et al. Hypoxic conditioning and the central nervous system: A new therapeutic opportunity for brain and spinal cord injuries? Exp Biol Med (Maywood) 2017; 242: 1198-1206. DOI: 10.1177/1535370217712691.

6. Pietrogrande G, Zalewska K, Zhao Z, et al. Low Oxygen Post Conditioning as an Efficient Non-pharmacological Strategy to Promote Motor Function After Stroke. Translational Stroke Research 2018. journal article. DOI: 10.1007/s12975-018-0656-5. 7. Galle AA and Jones NM. The neuroprotective actions of hypoxic preconditioning and postconditioning in a neonatal rat model of hypoxic-ischemic brain injury. Brain Res 2013; 1498: 1-8. DOI: 10.1016/j.brainres.2012.12.026.

8. Leconte C, Tixier E, Freret T, et al. Delayed hypoxic postconditioning protects against cerebral ischemia in the mouse. Stroke 2009; 40: 3349-3355. DOI: 10.1161/STROKEAHA.109.557314.

9. Rybnikova E, Vorobyev M, Pivina S, et al. Postconditioning by mild hypoxic exposures reduces rat brain injury caused by severe hypoxia. Neurosci Lett 2012; 513: 100105. DOI: 10.1016/j.neulet.2012.02.019.

10. Tsai YW, Yang YR, Sun SH, et al. Post ischemia intermittent hypoxia induces hippocampal neurogenesis and synaptic alterations and alleviates long-term memory impairment. J Cereb Blood Flow Metab 2013; 33: 764-773. 2013/02/28. DOI: $10.1038 / \mathrm{jcbfm} .2013 .15$

jcbfm201315 [pii].

11. Tsai YW, Yang YR, Wang PS, et al. Intermittent hypoxia after transient focal ischemia induces hippocampal neurogenesis and c-Fos expression and reverses spatial memory deficits in rats. PLoS One 2011; 6: e24001. DOI: 10.1371/journal.pone.0024001. 12. Lo EH. Experimental models, neurovascular mechanisms and translational issues in stroke research. Br J Pharmacol 2008; 153 Suppl 1: S396-405. 2007/12/25. DOI: 10.1038/sj.bjp.0707626.

13. Garcia-Alloza M, Gregory J, Kuchibhotla KV, et al. Cerebrovascular lesions induce transient beta-amyloid deposition. Brain 2011; 134: 3697-3707. 2011/11/29. DOI: 10.1093/brain/awr300.

14. Lesne S, Koh MT, Kotilinek L, et al. A specific amyloid-beta protein assembly in the brain impairs memory. Nature 2006; 440: 352-357. DOI: 10.1038/nature04533.

15. Nguyen HL, Ruhoff AM, Fath T, et al. Hypoxic postconditioning enhances functional recovery following endothelin-1 induced middle cerebral artery occlusion in conscious rats. Exp Neurol 2018; 306: 177-189. 2018/05/21. DOI: 10.1016/j.expneurol.2018.05.018. 16. Ong LK, Zhao Z, Kluge M, et al. Chronic stress exposure following photothrombotic stroke is associated with increased levels of Amyloid beta accumulation and altered 
oligomerisation at sites of thalamic secondary neurodegeneration in mice. J Cereb Blood Flow Metab 2017; 37: 1338-1348. DOI: 10.1177/0271678X16654920.

17. Zhao Z, Ong LK, Johnson S, et al. Chronic stress induced disruption of the periinfarct neurovascular unit following experimentally induced photothrombotic stroke. J Cereb Blood Flow Metab 2017: 271678X17696100. DOI: 10.1177/0271678X17696100.

18. Horner AE, Heath CJ, Hvoslef-Eide M, et al. The touchscreen operant platform for testing learning and memory in rats and mice. Nat Protoc 2013; 8: 1961-1984. DOI: 10.1038/nprot.2013.122.

19. Ong LK, Chow WZ, TeBay C, et al. Growth Hormone Improves Cognitive Function After Experimental Stroke. Stroke 2018; 49: 1257-1266. 2018/04/11. DOI: 10.1161/STROKEAHA.117.020557.

20. Oomen CA, Hvoslef-Eide M, Heath CJ, et al. The touchscreen operant platform for testing working memory and pattern separation in rats and mice. Nat Protoc 2013; 8: 20062021. DOI: $10.1038 /$ nprot.2013.124.

21. Tynan RJ, Naicker S, Hinwood M, et al. Chronic stress alters the density and morphology of microglia in a subset of stress-responsive brain regions. Brain, behavior, and immunity 2010; 24: 1058-1068. DOI: 10.1016/j.bbi.2010.02.001.

22. Franciosi S, De Gasperi R, Dickstein DL, et al. Pepsin pretreatment allows collagen IV immunostaining of blood vessels in adult mouse brain. J Neurosci Methods 2007; 163: 7682. DOI: 10.1016/j.jneumeth.2007.02.020.

23. Johnson SJ and Walker FR. Strategies to improve quantitative assessment of immunohistochemical and immunofluorescent labelling. Sci Rep 2015; 5: 10607. DOI: 10.1038/srep10607.

24. Kongsui R, Johnson SJ, Graham BA, et al. A combined cumulative threshold spectra and digital reconstruction analysis reveal structural alterations of microglia within the prefrontal cortex following low-dose LPS administration. Neuroscience 2015; 310: 629-640. DOI: 10.1016/j.neuroscience.2015.09.061.

25. Ong LK, Zhao Z, Kluge M, et al. Reconsidering the role of glial cells in chronic stress-induced dopaminergic neurons loss within the substantia nigra? Friend or foe? Brain, behavior, and immunity 2017; 60: 117-125. DOI: 10.1016/j.bbi.2016.10.001.

26. Zalewska K, Ong LK, Johnson SJ, et al. Oral administration of corticosterone at stress-like levels drives microglial but not vascular disturbances post-stroke. Neuroscience 2017. DOI: 10.1016/j.neuroscience.2017.03.005.

27. Zalewska K, Pietrogrande G, Ong LK, et al. Sustained administration of corticosterone at stress-like levels after stroke suppressed glial reactivity at sites of thalamic secondary neurodegeneration. Brain, behavior, and immunity 2018; 69: 210-222. 2017/11/23. DOI: $10.1016 /$ j.bbi.2017.11.014.

28. Pietrogrande G, Mabotuwana N, Zhao Z, et al. Chronic stress induced disturbances in Laminin: A significant contributor to modulating microglial pro-inflammatory tone? Brain, behavior, and immunity 2018; 68: 23-33. 2017/09/26. DOI: 10.1016/j.bbi.2017.09.012.

29. Barnett JH, Lewis L, Blackwell AD, et al. Early intervention in Alzheimer's disease: a health economic study of the effects of diagnostic timing. BMC Neurol 2014; 14: 101. DOI: 10.1186/1471-2377-14-101.

30. Pergola G, Gunturkun O, Koch B, et al. Recall deficits in stroke patients with thalamic lesions covary with damage to the parvocellular mediodorsal nucleus of the thalamus. Neuropsychologia 2012; 50: 2477-2491. DOI:

10.1016/j.neuropsychologia.2012.06.019.

31. Weinstein G, Preis SR, Beiser AS, et al. Cognitive performance after stroke--the Framingham Heart Study. Int J Stroke 2014; 9 Suppl A100: 48-54. DOI: 10.1111/ijs. 12275. 
32. Montgomery C, Fisk JE and Newcombe R. The nature of ecstasy-group related deficits in associative learning. Psychopharmacology (Berl) 2005; 180: 141-149. DOI: 10.1007/s00213-004-2131-0.

33. Rich JB, Campodonico JR, Rothlind J, et al. Perseverations during paired-associate learning in Huntington's disease. J Clin Exp Neuropsychol 1997; 19: 191-203. DOI: $10.1080 / 01688639708403850$.

34. LaManna JC, Vendel LM and Farrell RM. Brain adaptation to chronic hypobaric hypoxia in rats. J Appl Physiol (1985) 1992; 72: 2238-2243. 1992/06/01.

35. Arnold T and Betsholtz $\mathrm{C}$. The importance of microglia in the development of the vasculature in the central nervous system. Vasc Cell 2013; 5: 4. 2013/02/21. DOI: $10.1186 / 2045-824 X-5-4$.

36. Deczkowska A and Schwartz M. Making Ends Meet: Myeloid Cells Catalyze Blood Vessel Repair in the Brain. Immunity 2016; 44: 1081-1083. 2016/05/19. DOI:

10.1016/j.immuni.2016.04.024.

37. Jolivel V, Bicker F, Biname F, et al. Perivascular microglia promote blood vessel disintegration in the ischemic penumbra. Acta Neuropathol 2015; 129: 279-295. 2014/12/17. DOI: $10.1007 / \mathrm{s} 00401-014-1372-1$.

38. Kluge MG, Jones K, Kooi Ong L, et al. Age-dependent Disturbances of Neuronal and Glial Protein Expression Profiles in Areas of Secondary Neurodegeneration Post-stroke. Neuroscience 2018 2018/07/31. DOI: 10.1016/j.neuroscience.2018.07.034.

39. Ong LK, Walker FR and Nilsson M. Is Stroke a Neurodegenerative Condition? A Critical Review of Secondary Neurodegeneration and Amyloid-beta Accumulation after Stroke. AIMS Medical Science 2017; 4: 1-16. Review 11 January 2017 DOI: 10.3934/medsci.2017.1.1.

40. Back DB, Kwon KJ, Choi DH, et al. Chronic cerebral hypoperfusion induces poststroke dementia following acute ischemic stroke in rats. J Neuroinflammation 2017; 14: 216. 2017/11/11. DOI: 10.1186/s12974-017-0992-5.

41. Howe MD, Atadja LA, Furr JW, et al. Fibronectin induces the perivascular deposition of cerebrospinal fluid-derived amyloid- $\beta$ in aging and after stroke. Neurobiology of Aging 2018. DOI: https://doi.org/10.1016/j.neurobiolaging.2018.07.019.

42. Storck SE, Meister S, Nahrath J, et al. Endothelial LRP1 transports amyloid-beta(1-

42) across the blood-brain barrier. J Clin Invest 2016; 126: 123-136. DOI: 10.1172/JCI81108.

43. Iliff JJ, Wang M, Liao Y, et al. A paravascular pathway facilitates CSF flow through the brain parenchyma and the clearance of interstitial solutes, including amyloid beta. Sci Transl Med 2012; 4: 147ra111. DOI: 10.1126/scitranslmed.3003748.

44. Nagelhus EA and Ottersen OP. Physiological roles of aquaporin-4 in brain. Physiol Rev 2013; 93: 1543-1562. DOI: 10.1152/physrev.00011.2013.

45. Ergul A, Alhusban A and Fagan SC. Angiogenesis: a harmonized target for recovery after stroke. Stroke 2012; 43: 2270-2274. 2012/05/24. DOI:

10.1161/STROKEAHA.111.642710

STROKEAHA.111.642710 [pii].

46. Nakada Y, Canseco DC, Thet S, et al. Hypoxia induces heart regeneration in adult mice. Nature 2017; 541: 222-227. DOI: 10.1038/nature20173. 
Tables

Table I. List of antibodies used for western blot and immunohistochemistry.

\begin{tabular}{|l|l|l|l|}
\hline Target & Sources of antibodies & Application & Dilution \\
\hline Collagen IV & $\begin{array}{l}\text { Abcam, rabbit anti-collagen IV, } \\
\text { ab6586 }\end{array}$ & IHC & $1: 1000$ \\
\hline GFAP & Sigma, mouse anti-GFAP, G3893 & IHC & $1: 1500$ \\
\hline Iba-1 & WAKO, rabbit anti-Iba-1, 019-19741 & IHC & $1: 1000$ \\
\hline NeuN & Millipore, mouse anti-NeuN, MAB377 & IHC & $1: 500$ \\
\hline AQP4 & Millipore, rabbit anti- AQP4, AB3594 & IHC & $1: 1000$ \\
\hline IgG & $\begin{array}{l}\text { Abcam, biotinylated goat anti-mouse } \\
\text { IgG, ab64255 }\end{array}$ & IHC & $1: 500$ \\
\hline amyloid $\beta$ & $\begin{array}{l}\text { Cell Signaling Technology, anti- } \\
\text { amyloid } \beta \text { (D3D2N), \#15126 }\end{array}$ & WB & $1: 1000$ \\
\hline \multirow{\beta}{\beta}{-actin } & $\begin{array}{l}\text { Sigma-Aldrich, Monoclonal anti- } \beta- \\
\text { actin-HRP, A3854 }\end{array}$ & WB & $1: 50000$ \\
\hline Rabbit IgG & $\begin{array}{l}\text { Jackson ImmunoReseach, goat anti- } \\
\text { rabbit-biotin, \#111-065-003 }\end{array}$ & IHC & $1: 500$ \\
\hline Mouse IgG & $\begin{array}{l}\text { Biorad, anti-Mouse-HRP antibody, } \\
\# 170-6516\end{array}$ & WB & $1: 10000$ \\
\cline { 2 - 4 } & $\begin{array}{l}\text { Jackson ImmunoReseach, goat anti- } \\
\text { mouse-biotin, \#115-065-003 }\end{array}$ & IHC & $1: 500$ \\
\hline
\end{tabular}

WB, western blot; IHC, immunohistochemistry.

Table II. PCR primer sequences.

\begin{tabular}{|l|l|l|}
\hline Genes & Forward & Reverse \\
\hline APP & CCCACGACAGCAGCCAG & GCTCTGCCTCTTCCCATTC \\
\hline BACE1 & GCTTTGTGGAGATGGTGGAC & AGGATGTTGAGCGTCTGTGG \\
\hline TACE & CATCGTTGGGTCTGTTCTGG & AGGGATTCATACTGCTTGTC \\
\hline NEP & CTGGAGGTCAATGGGAAGTC & TCGGCTGAGGCTGCTTAC \\
\hline ECE & TCCTTCGCTGCCCTCCT & GGACAACATCAAAAGACCCAC \\
\hline IDE & AGTTCCCTGAGCACCCTTTC & ACCCAGCCCTTTGATTTGAG \\
\hline LRP1 & AGACTATCAGGGCGGCAAG & CAAACACGGACACGGAGAAC \\
\hline RAGE & CCGATGGCAAAGAAACACTC & GCAGGAGAAGGTAGGATGGG \\
\hline GAPDH & TCGGTGTGAACGGATTTGGC & TGTTAGTGGGGTCTCGCTCC \\
\hline
\end{tabular}

APP, amyloid precursor protein; BACE1, Beta-secretase 1; TACE, TNF $\alpha$ converting enzyme; NEP, neprilysin; ECE, endothelin-converting enzymes; IDE, insulin-degrading enzyme; LRP1, low-density lipoprotein receptor-related protein; RAGE, receptor for advanced glycation end products; GAPDH, glycolytic glyceraldehyde-3-phosphate dehydrogenase. 


\section{Figure Legends.}

Figure 1. Illustration of the PAL task. (a) The Campden Instruments touchscreen chamber apparatus. To obtain the strawberry milkshake reward, the animal needs to choose the correct stimulus on the touchscreen. An illustration of the two different trial types and the correct location object pairing (red crosses) in PAL. Graphs show the animals' performance of the four groups (sham, stroke, LOPC $8 \mathrm{~h}$ and LOPC 24h) in (b) \% correct rate, (c) repeated trials per task, (d) time per task and (e) latency of reward collection. Data expressed as mean \pm SD. ns: not significant, ${ }^{*} p<0.05, * * p<0.01$ (two-way ANOVA, Tukey's multiple comparisons).

Figure 2. Illustration of the neural tissue loss. (a) The stroke sections from Bregma $+1.0 \mathrm{~mm}$ to Bregma -2.0mm. (b) Representative labelling for NeuN for the four groups: sham, stroke, LOPC $8 \mathrm{~h}$ and LOPC 24h. (c) The graph shows that LOPC $8 \mathrm{~h}$ and LOPC $24 \mathrm{~h}$ animals had significant lower \% tissue loss compared to the stroke only animals. (d) The graph illustrates the total number of NeuN positive cells for four groups. Multiple peri-infarct regions (red boxes) at Bregma 0.0 were included for neuronal cell counts. Data expressed as mean \pm SD. $* * * p<0.001$ (one-way ANOVA, Tukey's multiple comparisons). White scale bar represents $300 \mu \mathrm{m}$ and black scale bar represents $1 \mathrm{~mm}$.

\section{Figure 3. The effects of LOPC on vascular and glial cells within the peri-infarct regions.}

Four left panels in each row illustrate representative labelling for each marker investigated (a) Collagen IV, (d) GFAP and (g) Iba-1 for the four groups: sham, stroke, LOPC $8 \mathrm{~h}$ and LOPC 24h. The first set of graphs (b, e, h) show quantification of the fold change of thresholded material for each of the markers. The second set of graphs show (c) percentage of area covered by Collagen IV positive cells, and number of (f) GFAP positive cells and (i) 
Iba-1 positive cells. Data expressed as a fold change of mean \pm SD for each group relative to the mean of the sham group. For cumulative threshold analysis refer to the Supplementary material. $* p<0.05, * * * p<0.001$ (ANOVA, Tukey's multiple comparisons). All scale bars represent $100 \mu \mathrm{m}$.

Figure 4. LOPC reduces $A \beta$ in the peri-infarct territory after stroke. (a) The left panel is the representative western blot of protein samples in peri-infarct territory from sham, stroke, LOPC $8 \mathrm{~h}$ and LOPC $24 \mathrm{~h}$ animals. Bands were detected using D3D2N anti-A $\beta$ antibody. Loading controls were performed by analysis of $\beta$-actin. The bar graphs at the right are quantification of $\mathrm{A} \beta$ oligomers at (b) $56 \mathrm{kDa}$ (dodecamer), (c) $50 \mathrm{kDa}$ (decamer), (d) $25 \mathrm{kDa}$ (pentamer), (e) $5 \mathrm{kDa}$ (monomer) and (f) total $\mathrm{A} \beta(5-200 \mathrm{kDa})$ deposition. Data expressed as a fold change of mean $\pm \mathrm{SD}$ for each group relative to the mean of the sham group. ns: not significant, $\quad * p<0.05, \quad * * p<0.01 \quad * * * p<0.001 \quad$ (one-way ANOVA, Tukey's multiple comparisons).

Figure 5. The expression levels of genes involved in the generation, degradation and export of A $\boldsymbol{\beta}$. The expression of (a) amyloid precursor protein, APP; (b) beta-secretase, BACE; (c) TNF $\alpha$ converting enzyme, TACE; (d) neprilysin, NEP; (e) endothelin-converting enzyme, ECE; (f) insulin-degrading enzyme, IDE; (g) low-density lipoprotein receptorrelated protein-1, LRP1; and (h) receptor for advanced glycation end products, RAGE. Data expressed as a fold change of mean $\pm \mathrm{SD}$ for each group relative to the mean of the sham group. ns: not significant, $* p<0.05, * * * p<0.001$ (one-way ANOVA, Tukey's multiple comparisons).

Figure 6. LOPC improves vascular leakage and AQP4 polarity within peri-infarct 
region following stroke. (a) Images illustrate representative labelling of $\operatorname{IgG}$ staining, an index of cerebrovascular leakage. (b) Images illustrate representative labelling of AQP4. Insets show APQ4 polarity on vessels at high magnification. The right bar graph illustrates the AQP4 polarization. Data expressed as a fold change of mean \pm SD for each group relative to the mean of the sham group. ns: not significant, $* p<0.05$, ** $p<0.01 * * * p<0.001$ (one-way ANOVA, Tukey's multiple comparisons). Black scale bar represents $100 \mu \mathrm{m}$ and white scale bar represents of inset represents $10 \mu \mathrm{m}$.

Figure 7. Cumulative threshold analysis. Left panels show the percentage of material thresholded of (a) Collagen IV, (b) IgG, (c) GFAP and (d) Iba-1 immunolabels at different levels of pixel intensity (PI). Dotted line are PI level considered to be optimal for detecting genuine differences in immunoreactive signal. The right most panel illustrates quantification of the change $\%$ of thresholded material for each of the immunolabels at selected PI. Data for left panels are presented as mean and data for right panels are presented as mean \pm SD.

$* \mathrm{p}<0.05, * * * \mathrm{p}<0.001$ (ANOVA followed by Tukey's multiple comparisons). 
(a)

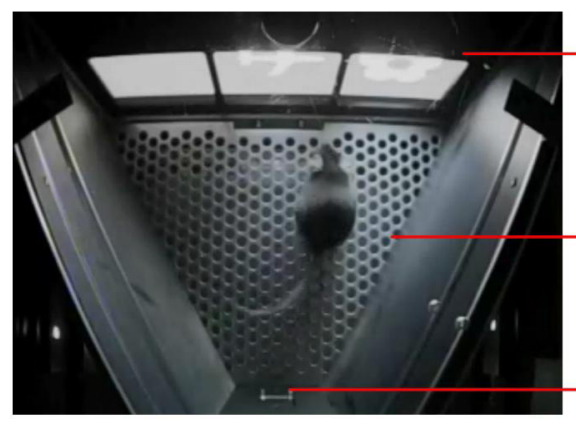

$+$

(0) $\frac{((n))}{(1)}$

(2) (ii) (b)

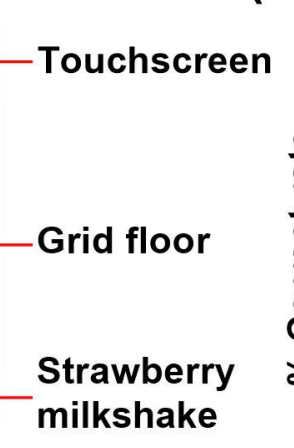

(c)
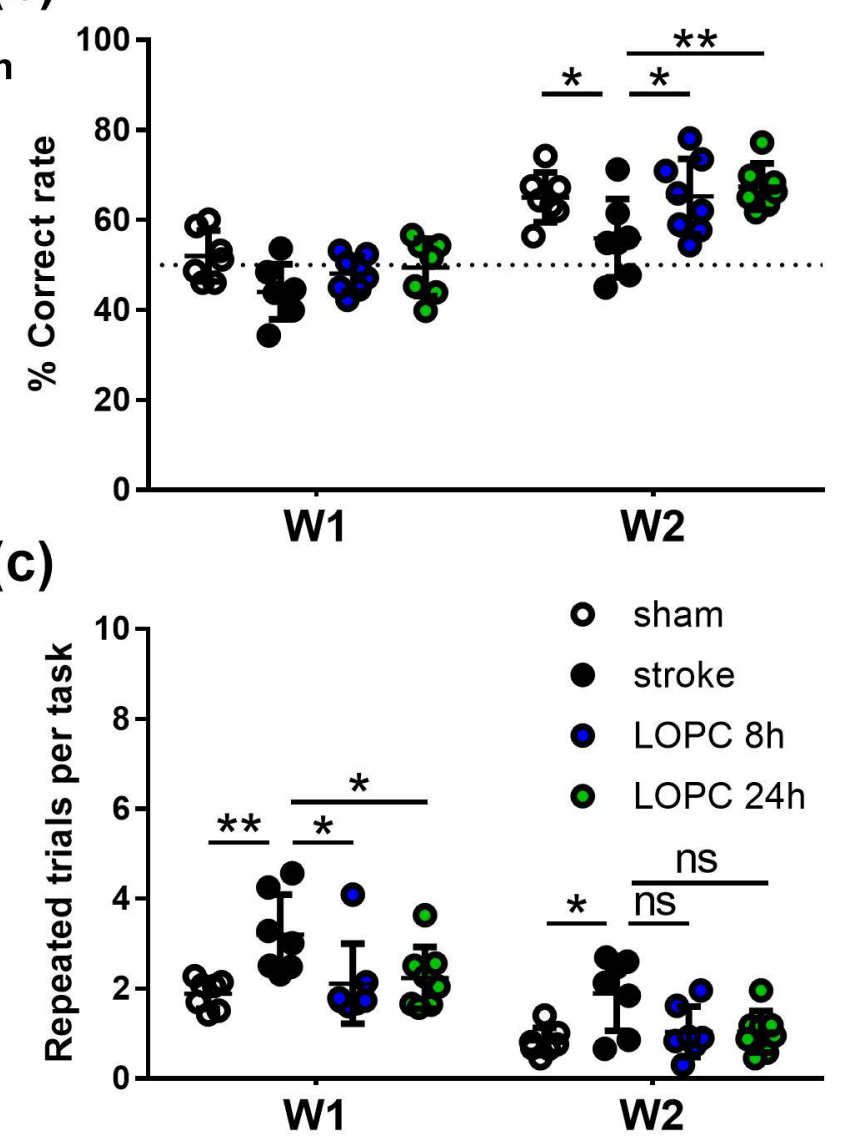

(d)

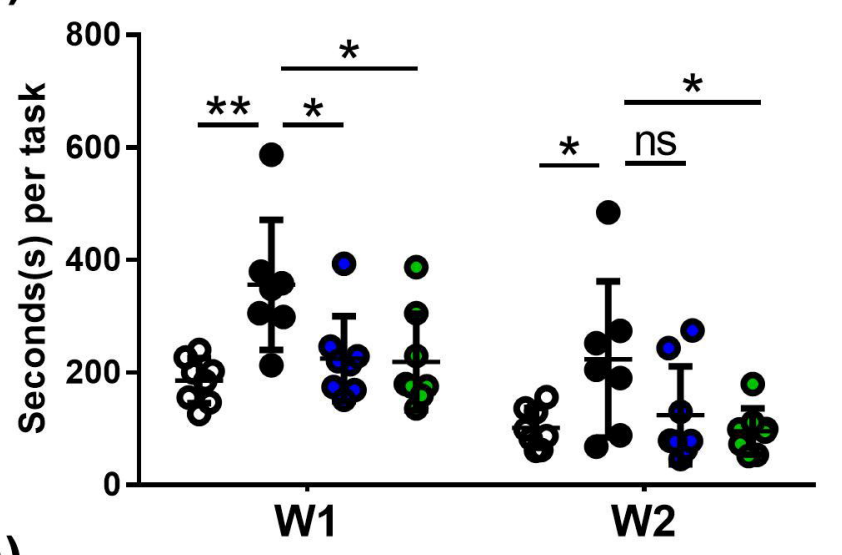

(e)

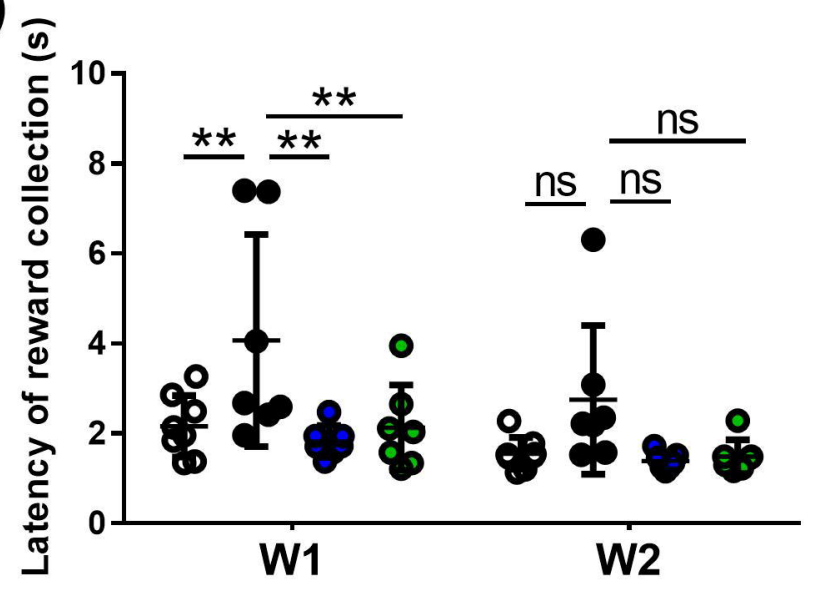


(a)
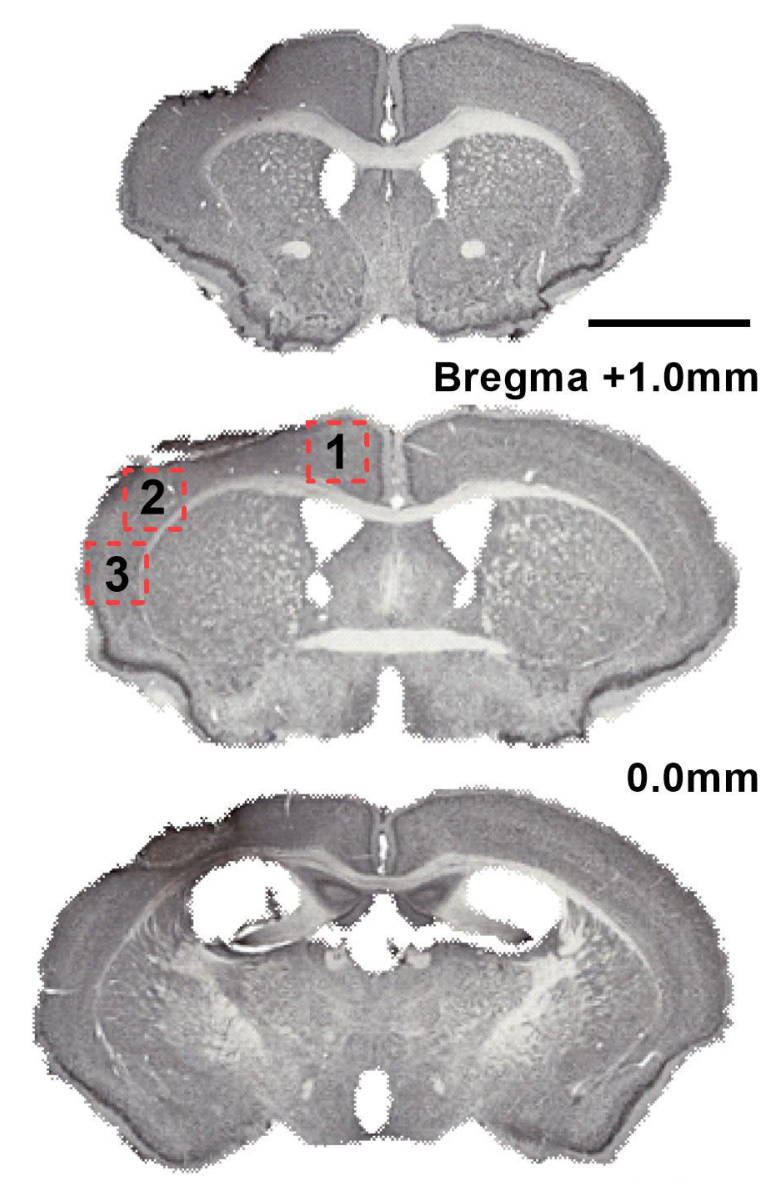

$-1.0 \mathrm{~mm}$

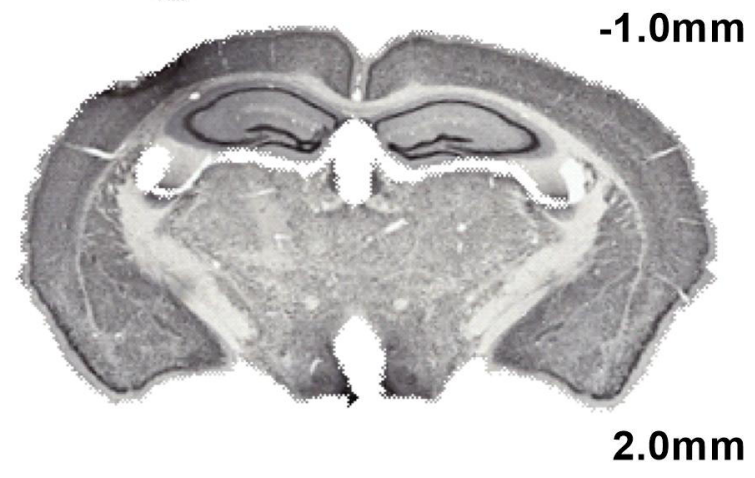

\section{(b) NeuN}

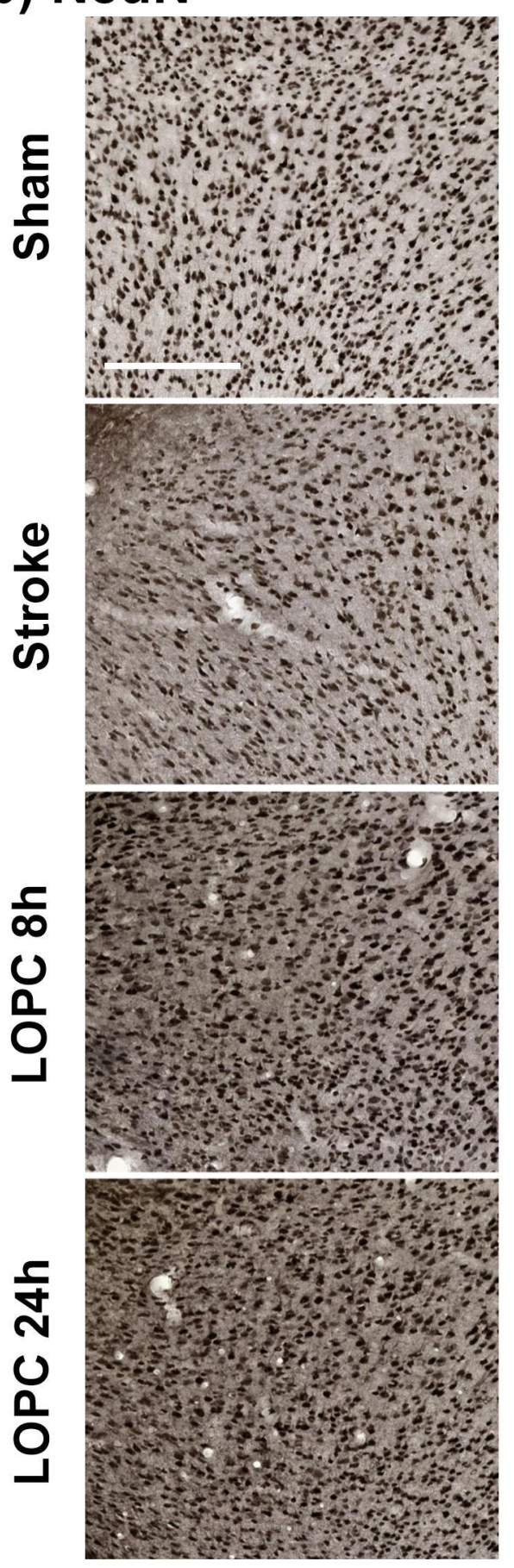

(c)

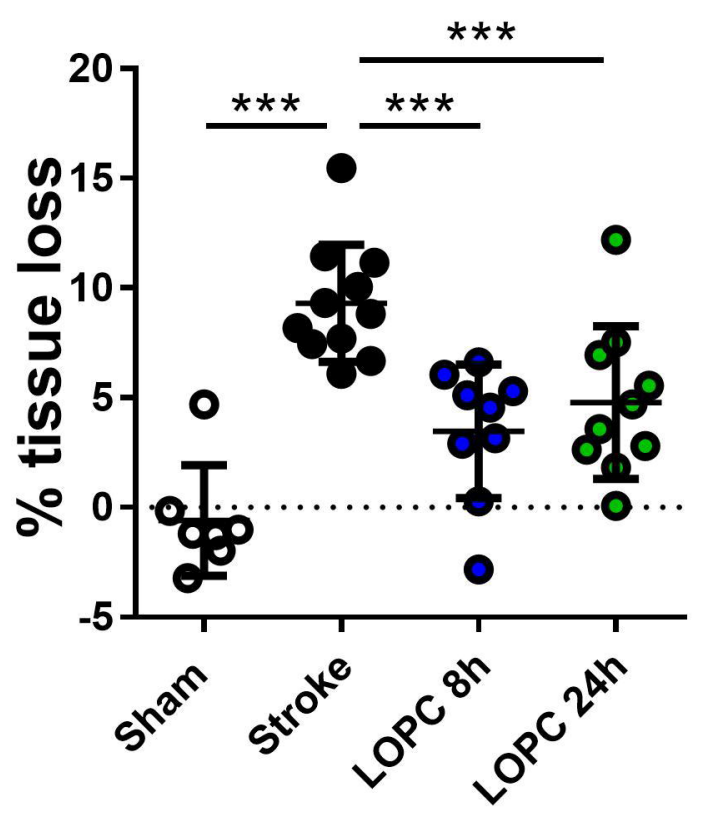

(d)

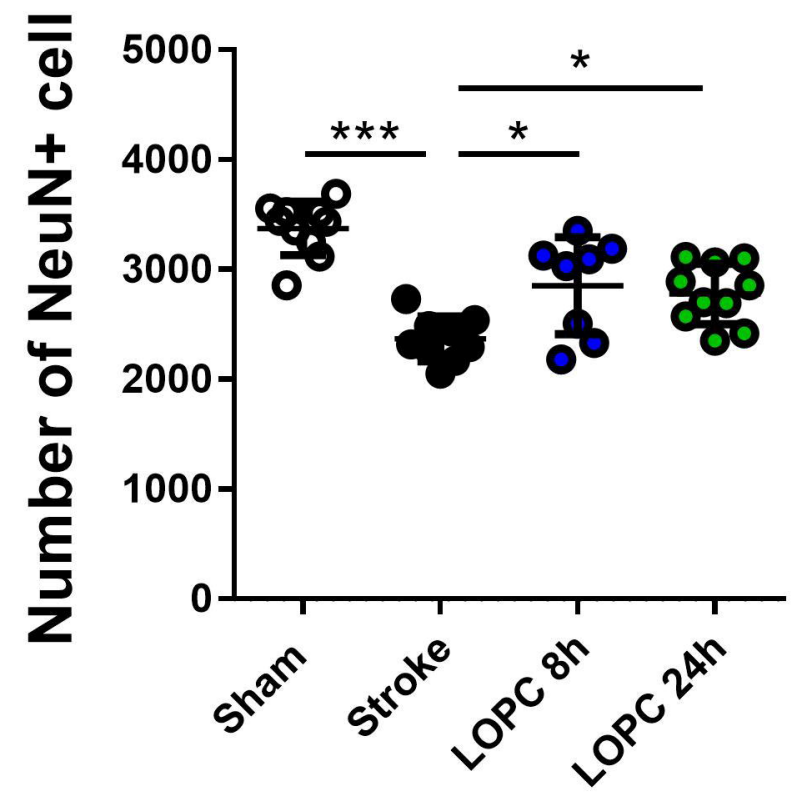


(a) Collagen IV

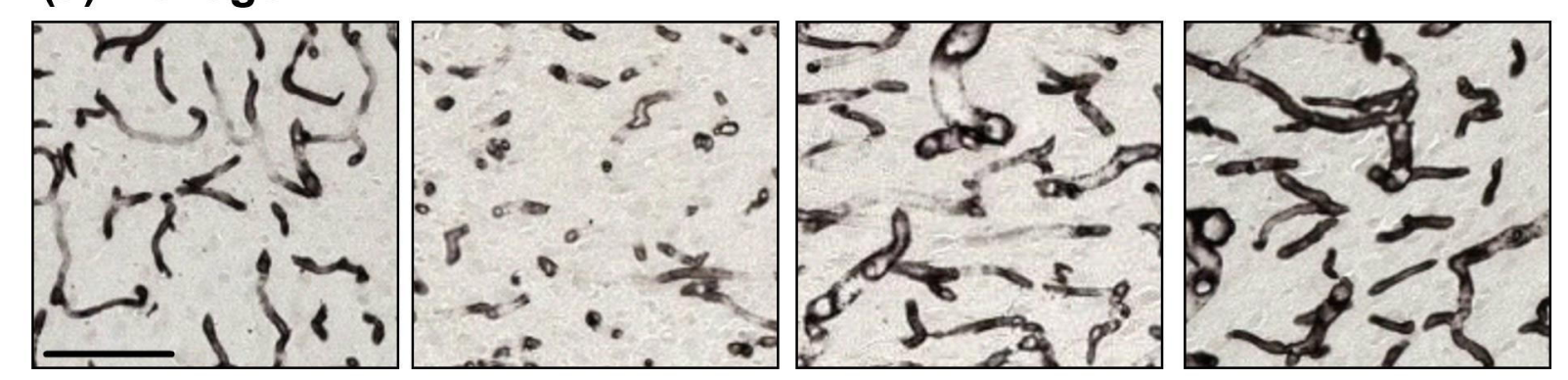

(d) GFAP

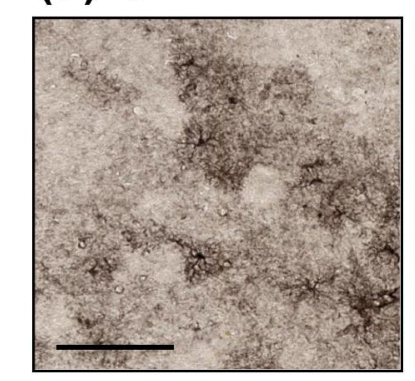

(g) Iba-1

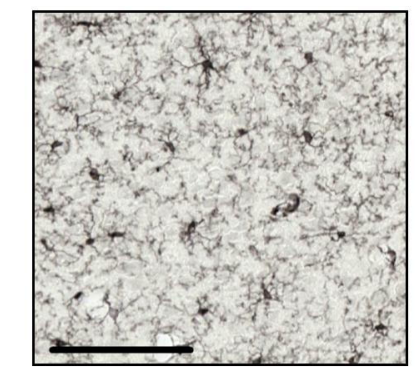

Sham
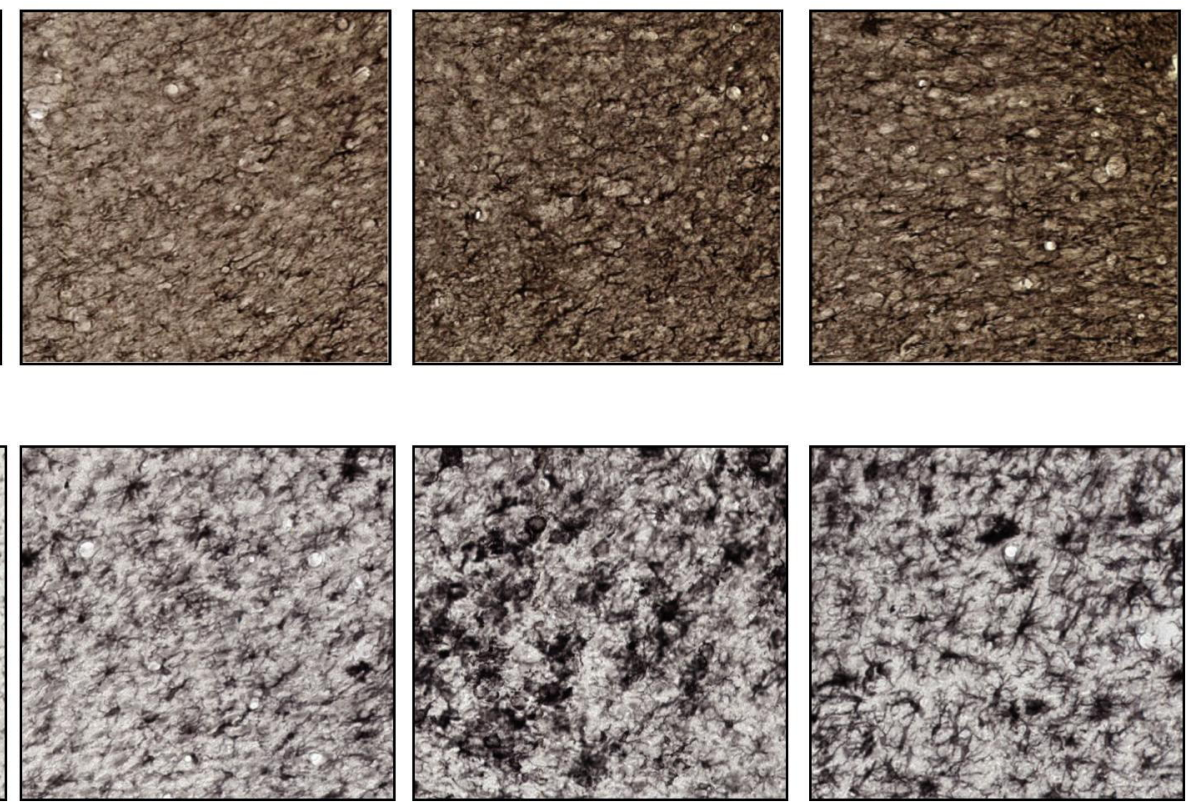

Stroke

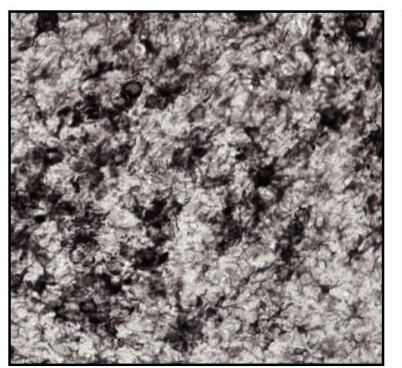

LOPC 8h

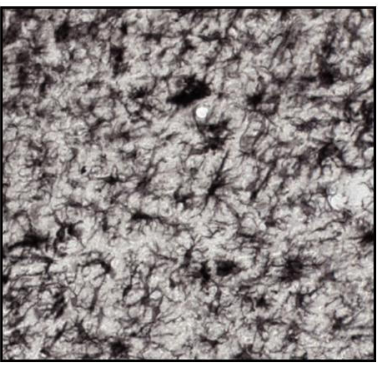

LOPC 24h (h)

(b)

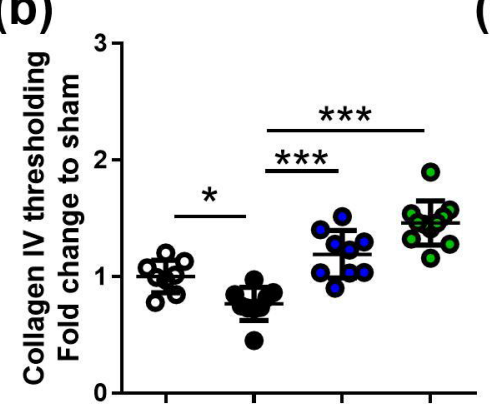

(e)

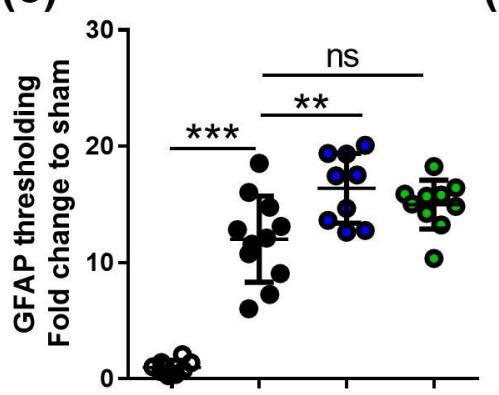

(c)

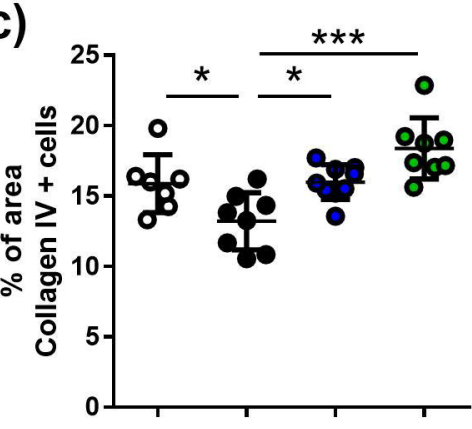

(f)

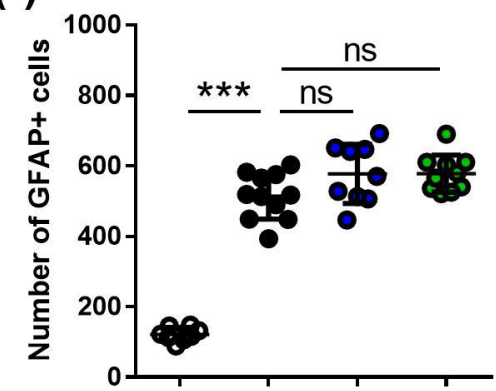

(i)

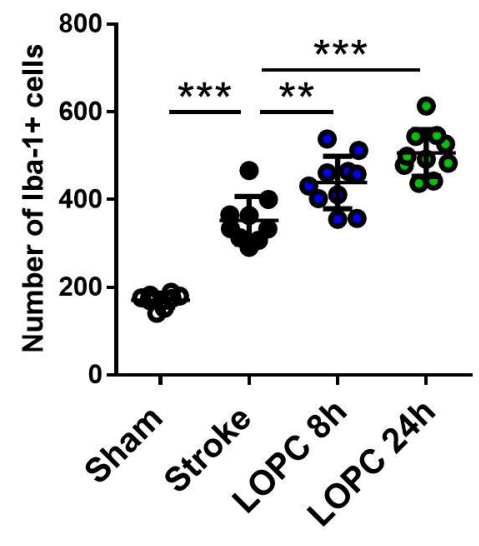


(a)

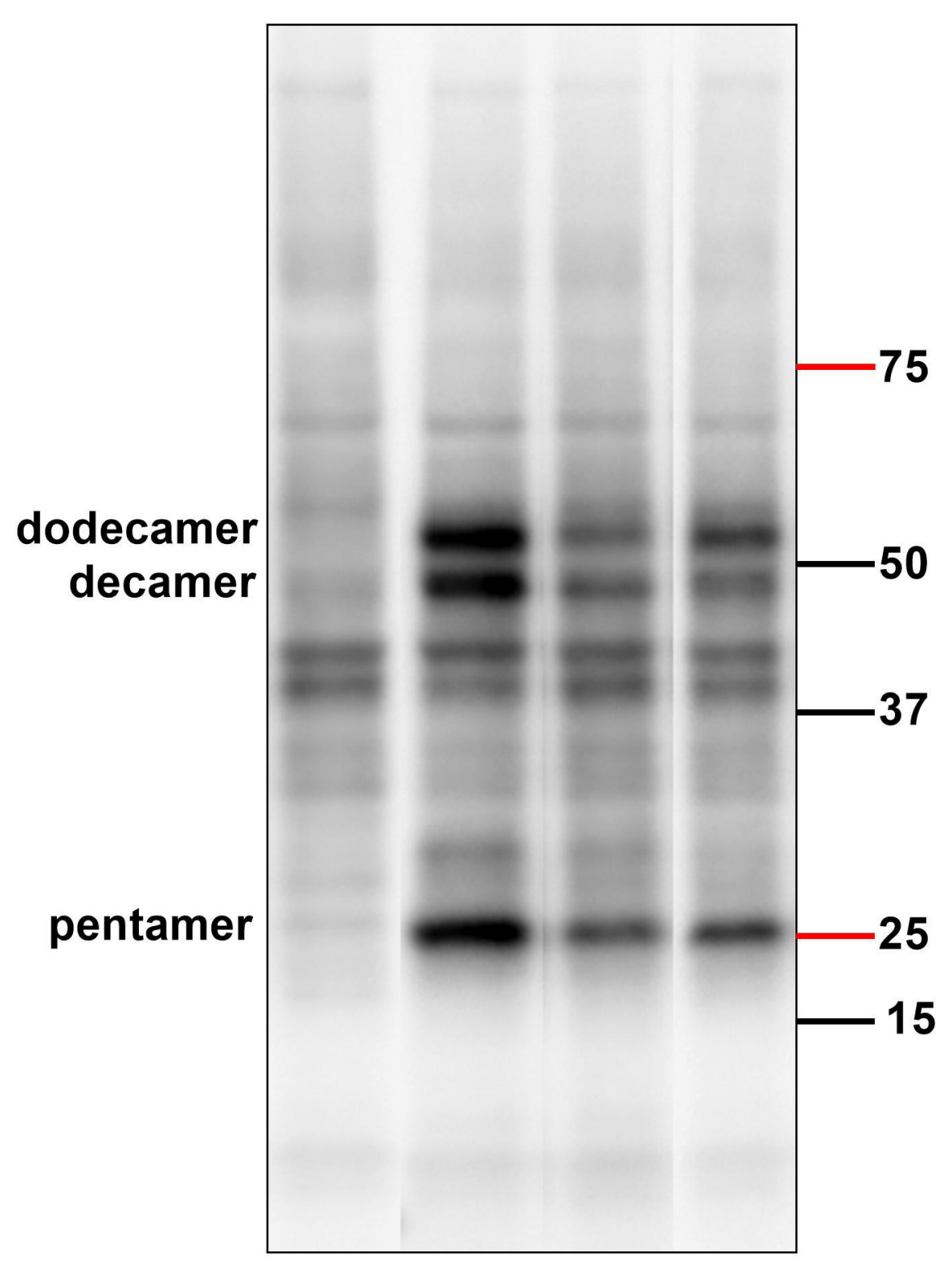

monomer

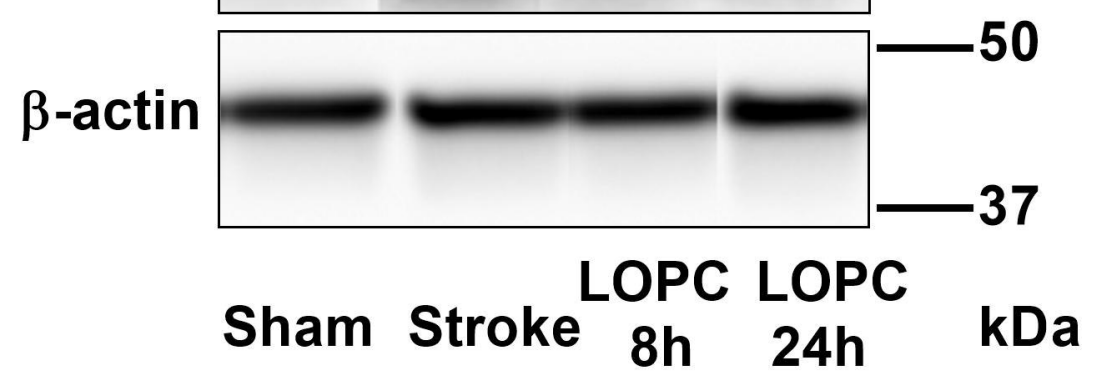

(b)

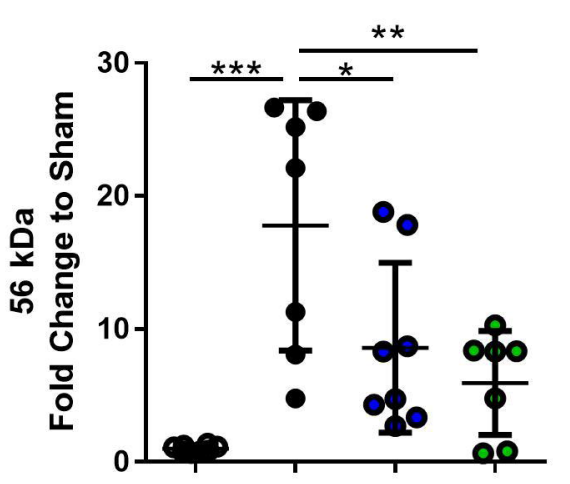

(c)

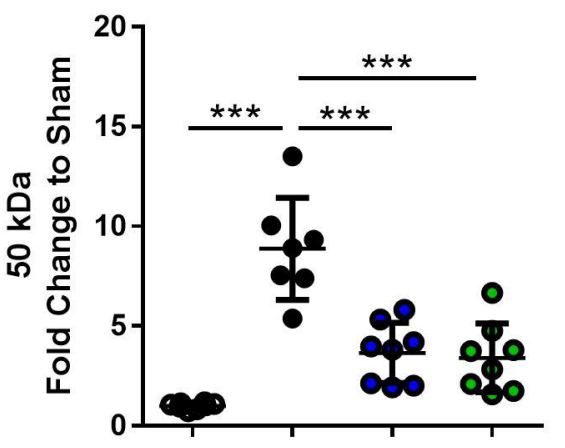

(d)

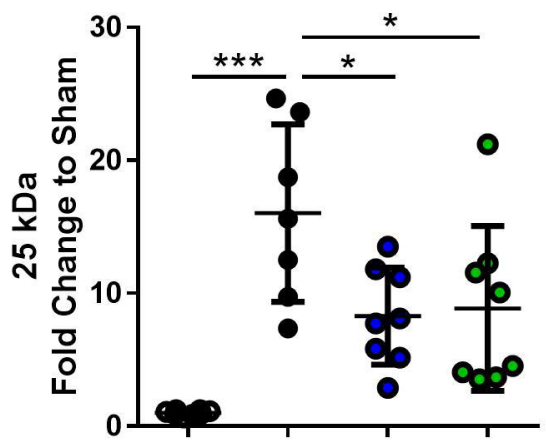

(e)

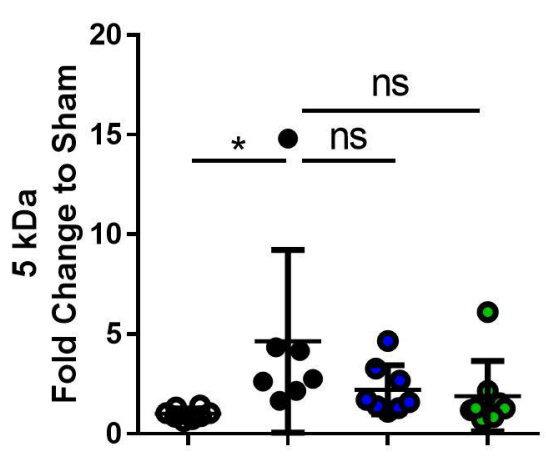

(f)

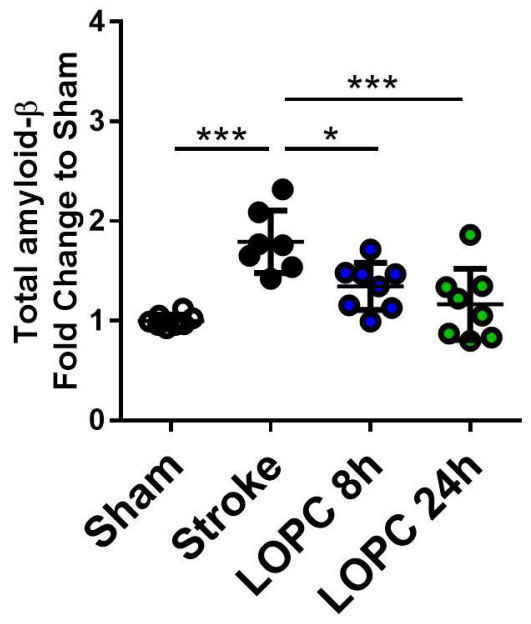


(a)

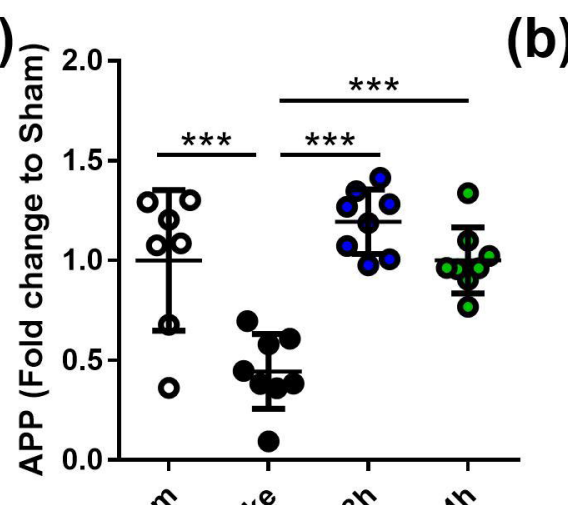

(d)

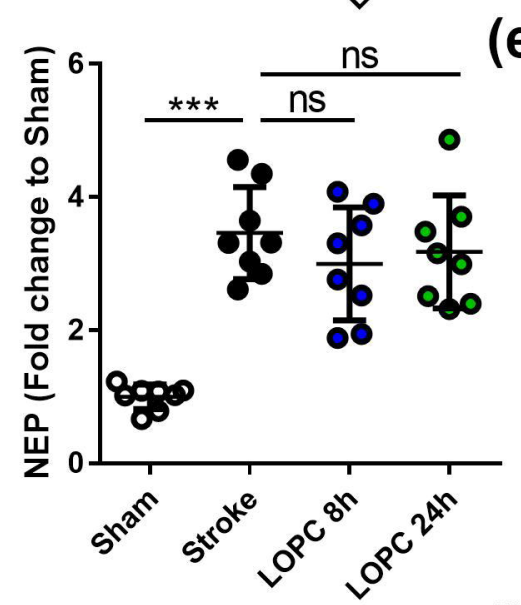

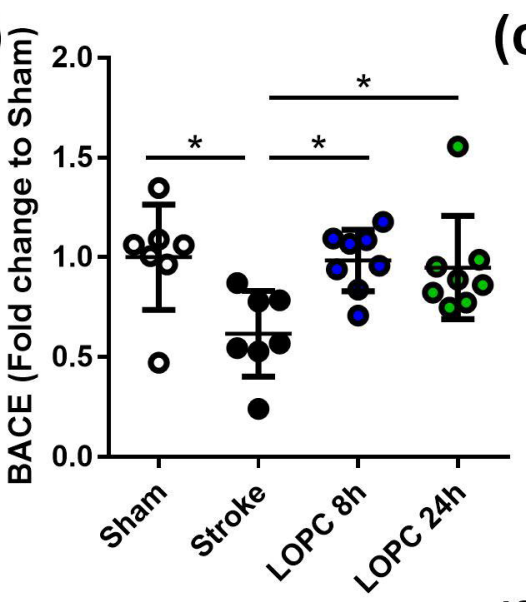

(e)

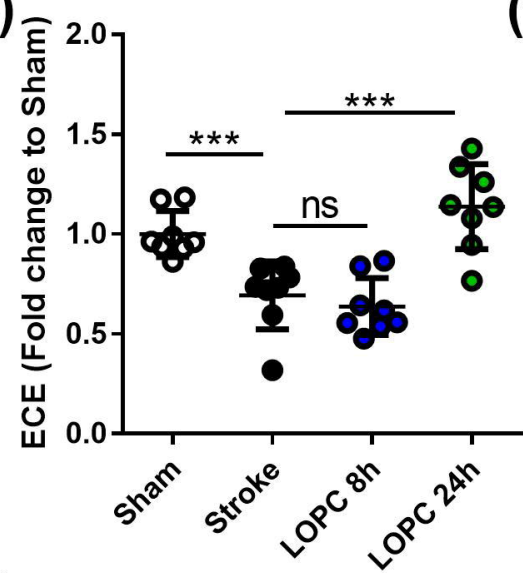

(h)

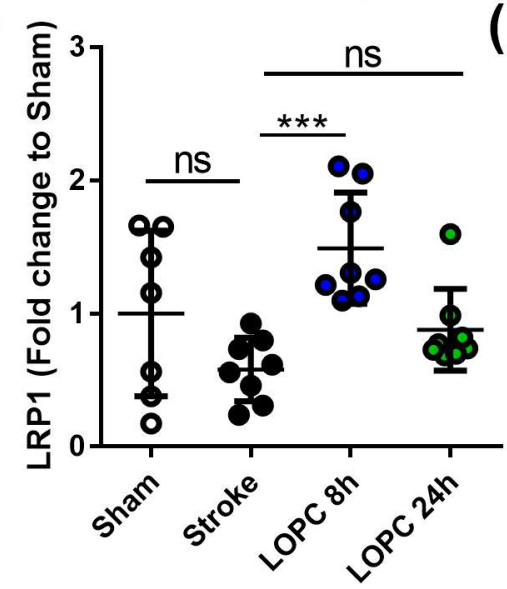

(g)

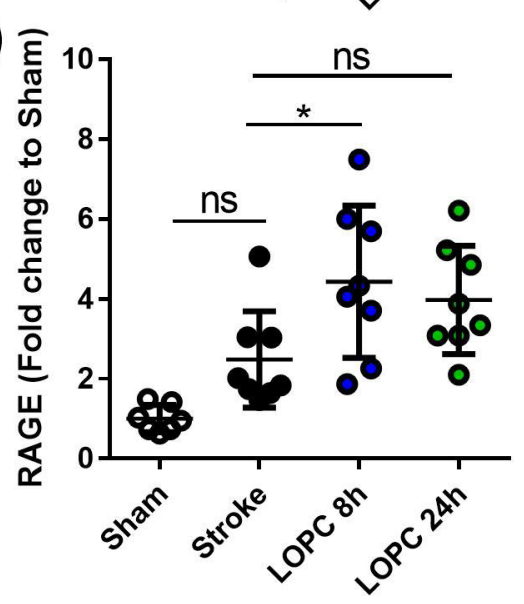

(c)

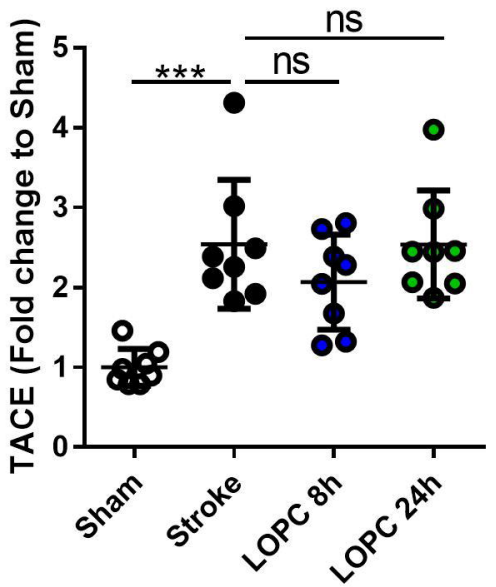

(f)

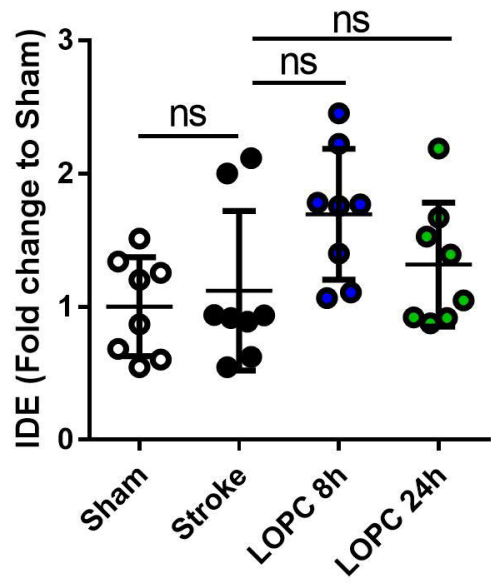


(a) $\lg G$

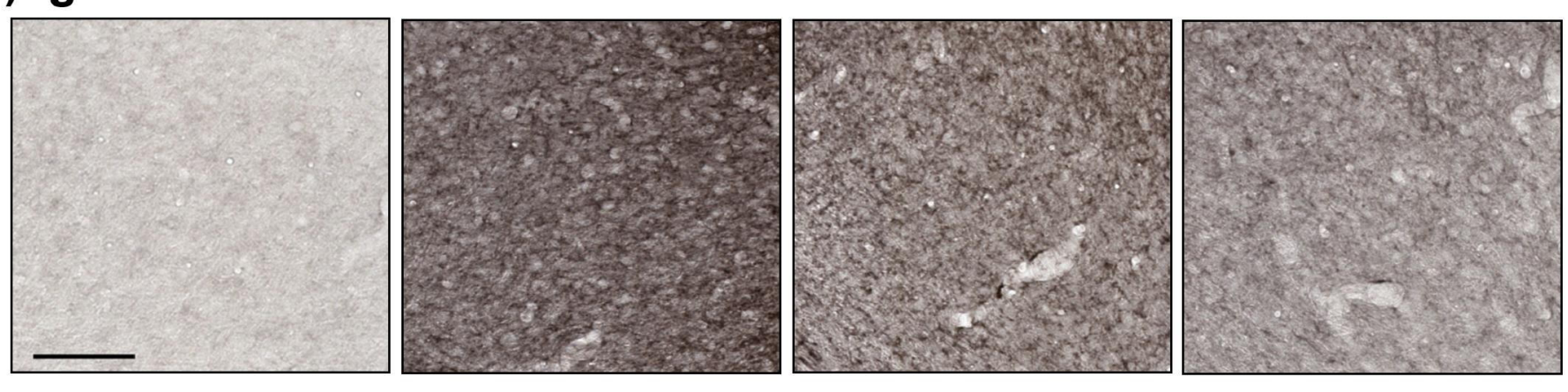

(b) AQP4

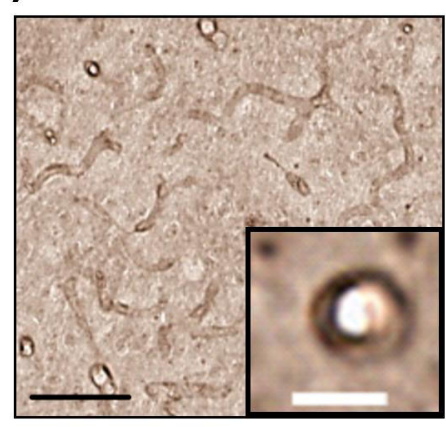

Sham

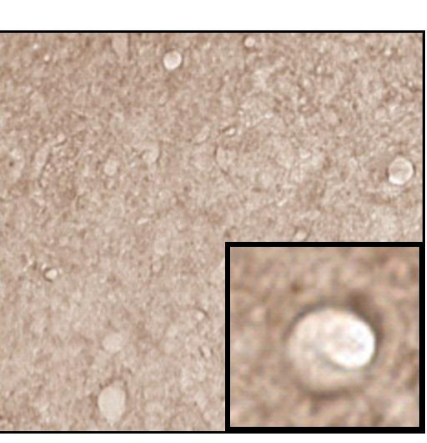

Stroke

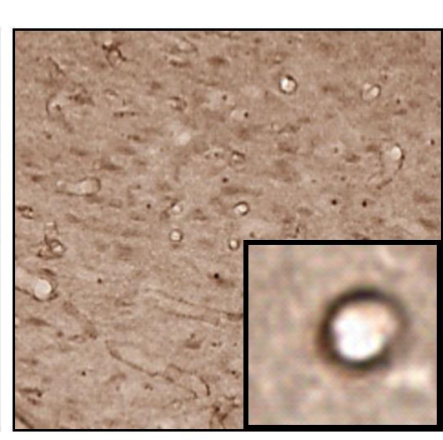

LOPC $8 \mathrm{~h}$
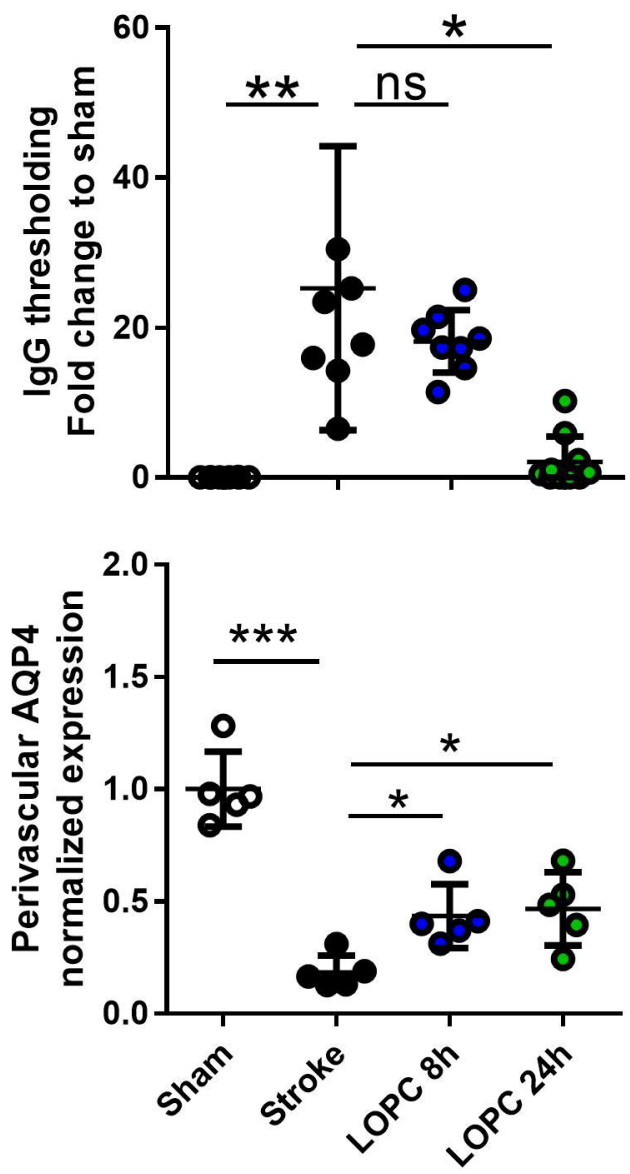


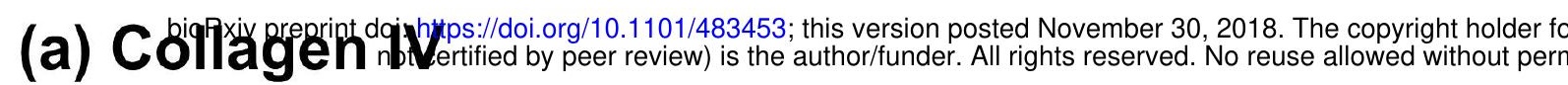
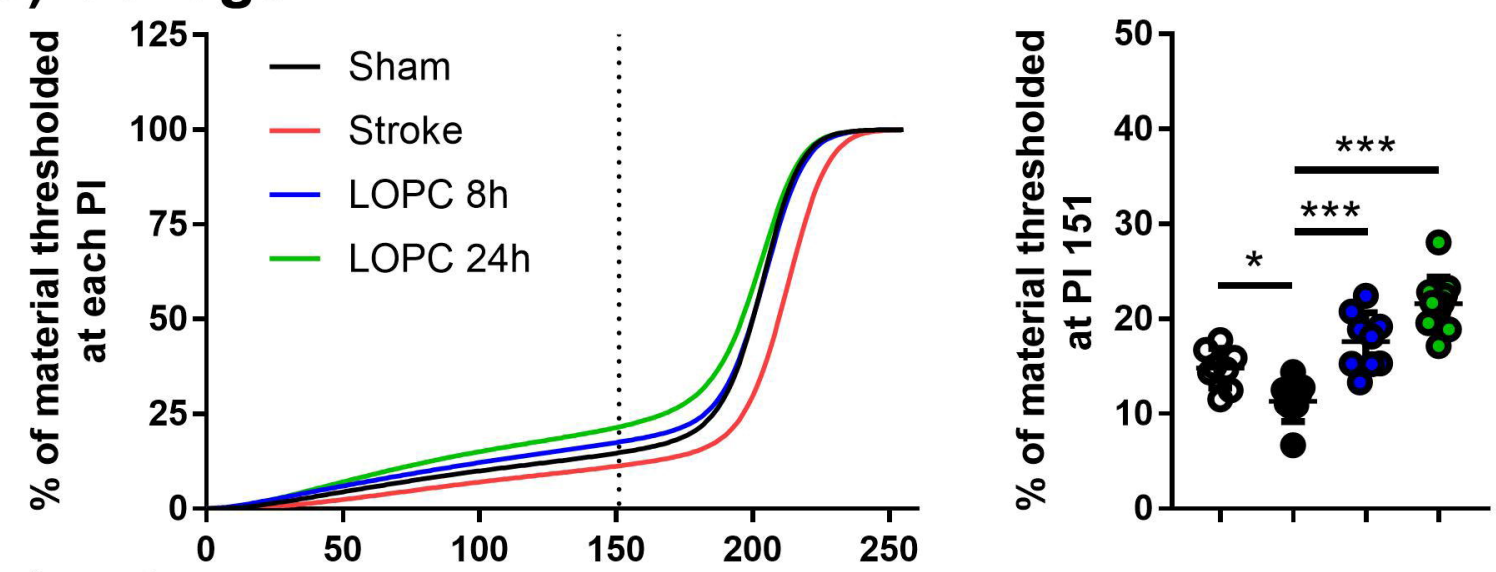

(b) $\lg G$
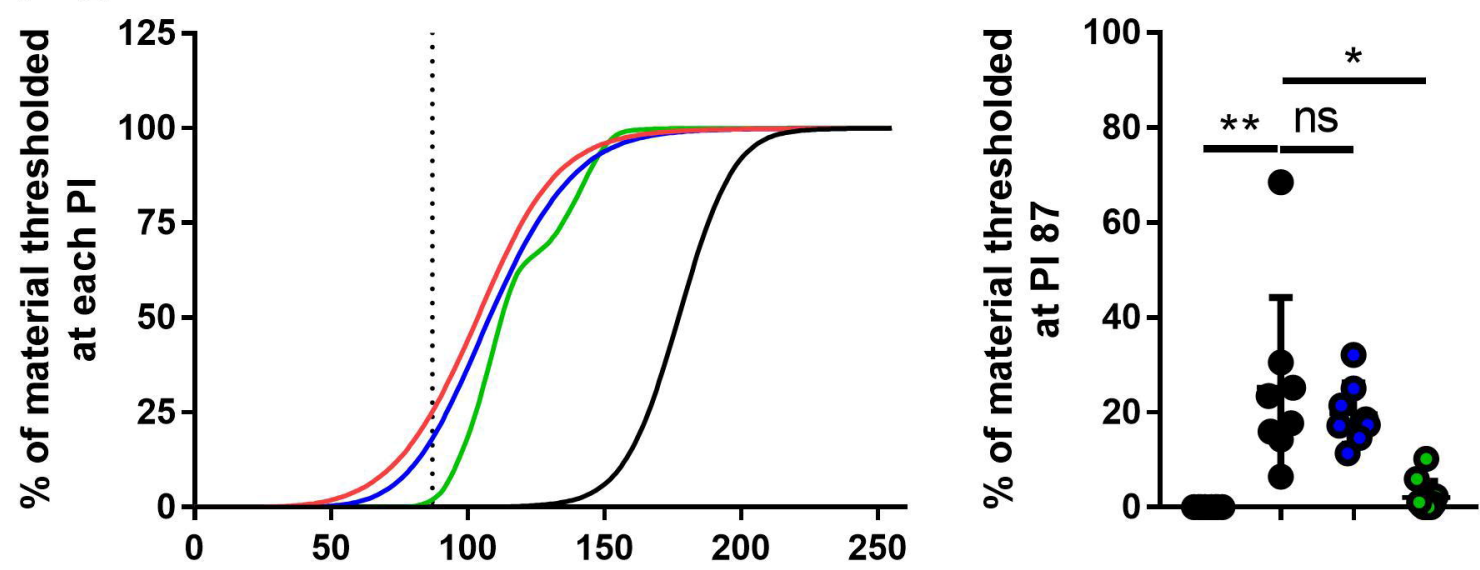

(c) GFAP
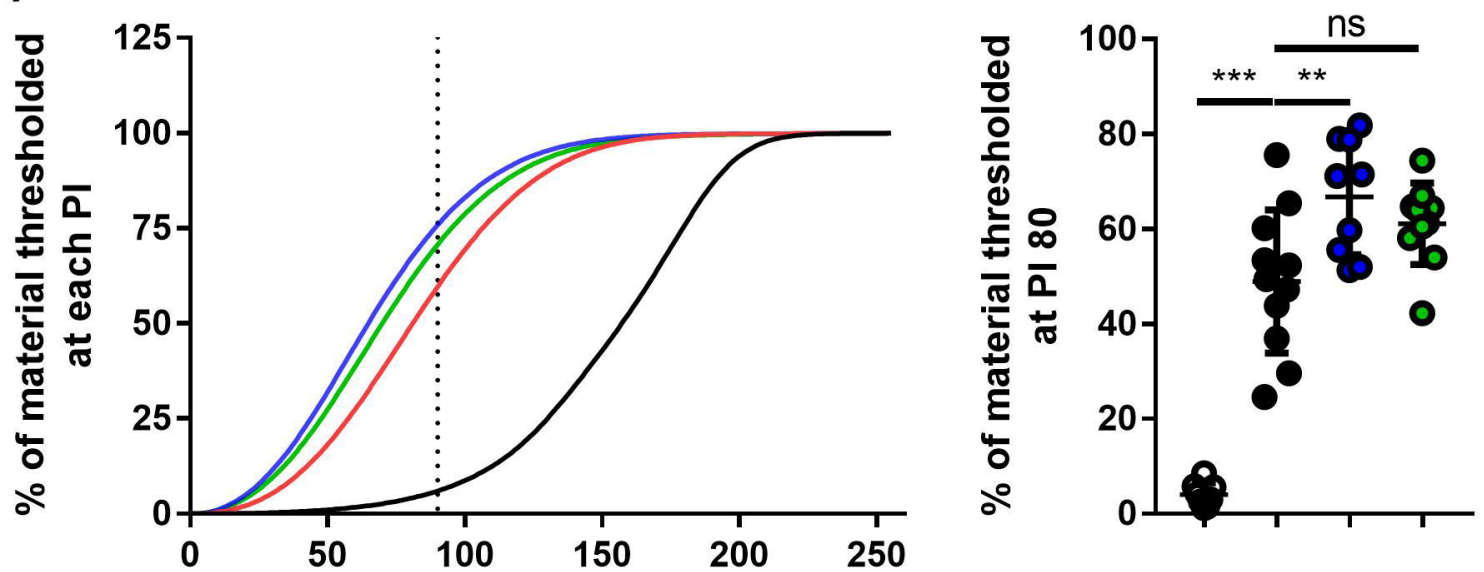

(d) Iba-1
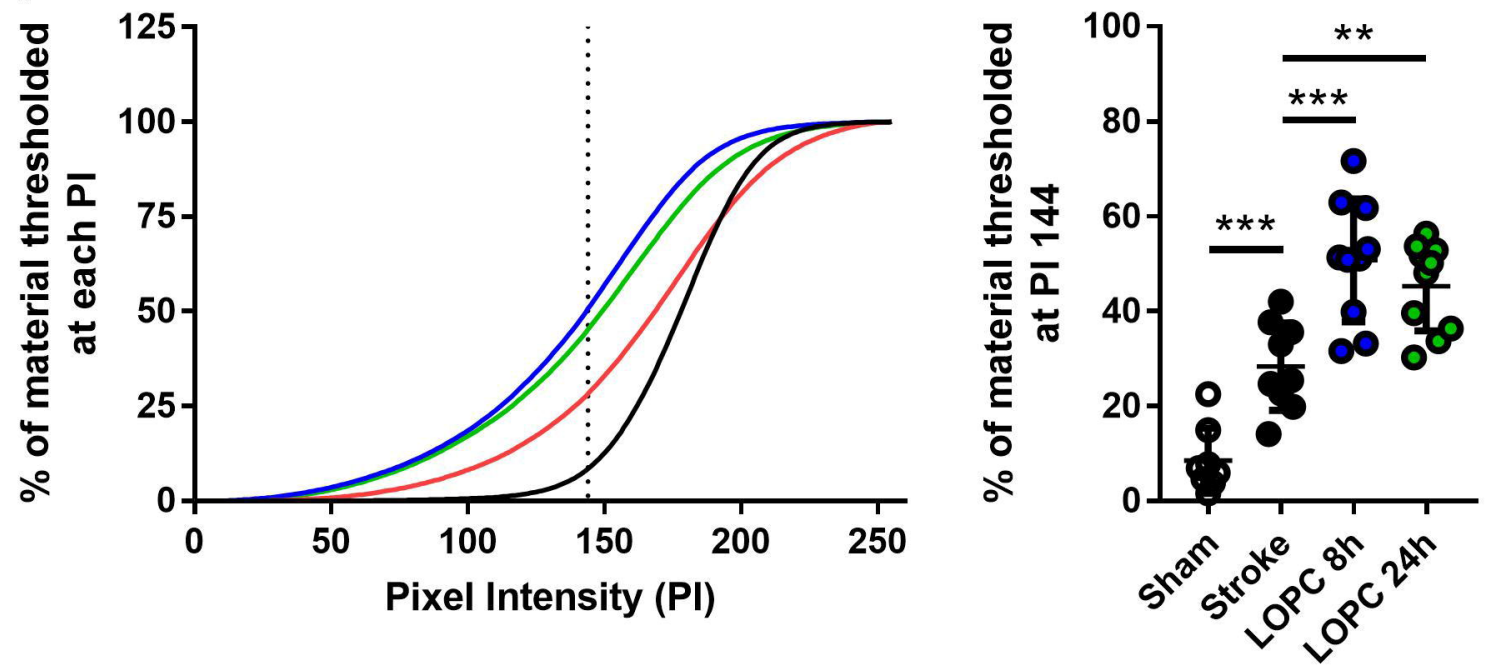